ARTICLE

DOI: $10.1038 / \mathrm{s} 41467-018-04476-2$

OPEN

\title{
High energy-density and reversibility of iron fluoride cathode enabled via an intercalation- extrusion reaction
}

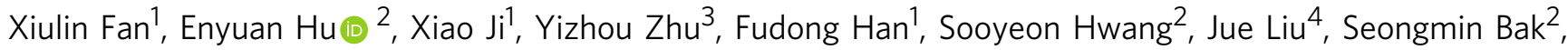

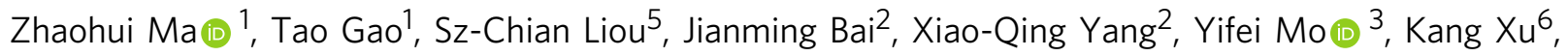
Dong Su (i) ${ }^{2} \&$ Chunsheng Wang (i) ${ }^{1}$

Iron fluoride, an intercalation-conversion cathode for lithium ion batteries, promises a high theoretical energy density of $1922 \mathrm{Wh} \mathrm{kg}^{-1}$. However, poor electrochemical reversibility due to repeated breaking/reformation of metal fluoride bonds poses a grand challenge for its practical application. Here we report that both a high reversibility over 1000 cycles and a high capacity of $420 \mathrm{mAh} \mathrm{g}^{-1}$ can be realized by concerted doping of cobalt and oxygen into iron fluoride. In the doped nanorods, an energy density of $\sim 1000 \mathrm{Wh} \mathrm{kg}^{-1}$ with a decay rate of $0.03 \%$ per cycle is achieved. The anion's and cation's co-substitutions thermodynamically reduce conversion reaction potential and shift the reaction from less-reversible intercalationconversion reaction in iron fluoride to a highly reversible intercalation-extrusion reaction in doped material. The co-substitution strategy to tune the thermodynamic features of the reactions could be extended to other high energy conversion materials for improved performance.

\footnotetext{
${ }^{1}$ Department of Chemical and Biomolecular Engineering, University of Maryland, College Park, MD 20742, USA. ${ }^{2}$ Brookhaven National Laboratory, Upton, NY 11973, USA. ${ }^{3}$ Department of Materials Science and Engineering, University of Maryland, College Park, MD 20742, USA. ${ }^{4}$ Chemical and Engineering Materials Division, Oak Ridge National Laboratory, Oak Ridge, TN 37831, USA. ${ }^{5}$ Maryland Nanocenter, University of Maryland, College Park, MD 20742, USA. ${ }^{6}$ Electrochemistry Branch, Power and Energy Division Sensor and Electron Devices Directorate, U.S. Army Research Laboratory, Adelphi, MD 20783, USA. These authors contributed equally: Xiulin Fan, Enyuan Hu. Correspondence and requests for materials should be addressed to

D.S. (email: dsu@bnl.gov) or to C.W. (email: cswang@umd.edu)
} 
ithium ion batteries (LIBs) have dominated portable electronics, and are penetrating the markets of electric vehicles. Current LIB cathodes such as $\mathrm{LiCoO}_{2}, \mathrm{LiFePO}_{4}$, or $\mathrm{LiNi}_{x} \mathrm{Mn}_{y} \mathrm{Co}_{1-x-y} \mathrm{O}_{2}$ are exclusively based on intercalation mechanism, which involves topotactic intercalation/deintercalation of $\mathrm{Li}^{+}$in a host lattice. However, these cathodes have specific capacities ranged only from 140 to $200 \mathrm{mAh} \mathrm{g}^{-1}$, which limit their energy densities ${ }^{1,2}$. Alternatively, certain metallic oxide, sulfide, or halide compounds can experience conversion reactions with $\mathrm{Li}^{+}$by accepting multiple electrons per formula, delivering much higher capacities. These conversion reaction compounds, represented as $\mathrm{MX}_{y}(\mathrm{M}=$ transition metals, $\mathrm{X}=\mathrm{N}, \mathrm{F}, \mathrm{O}, \mathrm{S}$, etc.), are converted to a nanocomposite containing reduced $\mathrm{M}^{0}$ and $\mathrm{Li}_{z} \mathrm{X}$ after discharge (Eq. 1$)^{3}$ :

$$
\mathrm{M}^{y+} \mathrm{X}^{z-}{ }_{y / z}+y \mathrm{Li}^{+}+y \mathrm{e}^{-} \longleftrightarrow \mathrm{M}^{0}+y / z \mathrm{Li}_{z} \mathrm{X}
$$

Among them, iron trifluoride $\left(\mathrm{FeF}_{3}\right)$, cheap and environmentally friendly, appears to be unique as a cathode candidate with a total theoretical energy density of $1922 \mathrm{Wh} \mathrm{kg}$ -1 and a relatively high working potential due to its ionic nature ${ }^{4}$. Its lithiation process goes through two successive intercalation and conversion reactions. In the intercalation reaction at $\sim 3.0 \mathrm{~V}, \mathrm{FeF}_{3}$ is lithiated into $\mathrm{LiFeF}_{3}$ providing a capacity of $237 \mathrm{mAh} \mathrm{g}^{-1}$. With further lithiation to below $2.0 \mathrm{~V}$, the $\mathrm{LiFeF}_{3}$ will decompose into $\mathrm{Fe}$ and $\mathrm{LiF}$ through a conversion reaction providing another 475 mAh g $^{-1}$ (Eq. 2) $)^{5}$.

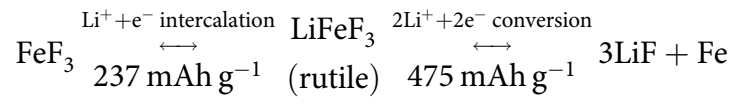

Although extensive researches have been conducted, only limited performance improvement was achieved due to several intrinsic issues of conversion reaction: (1) a severe voltage hysteresis $(\sim 1.3 \mathrm{~V})$ between the lithiation and delithiation processes, thus a low round-trip energy efficiency of $<60 \%$ was always observed ${ }^{6-8}$, due to the slow phase separation and repeated breaking/reforming of $\mathrm{Fe}-\mathrm{F}$ bonds in each conversion reaction cycle ${ }^{9,10}$; (2) sluggish conversion reaction kinetics, which is caused by both poor electronic conduction, low ion diffusivity in $\mathrm{FeF}_{3}{ }^{8}$, and the slow conversion phase transition, leads to extremely poor rate capabilities ${ }^{7,11-13}$; (3) the aggregation and continuous coarsening of $\mathrm{Fe}$ nanoparticles ${ }^{13,14}$ during repeated conversion reaction cycles, and sustained reactions of Fe with electrolytes ${ }^{15,16}$, result in the rapid capacity decay during cycling ${ }^{4,16-30}$. Partial substitution of fluorine with oxygen $\left(\mathrm{FeO}_{x} \mathrm{~F}_{2-x}(0.4<x<0.7)\right)$ enable the formation of an intermediate rocksalt phase through a reversible extrusion reaction before the conversion reaction of rocksalt phase. During cell discharge, the incoming $\mathrm{Li}^{+}$enter the parent phase and prompt the precipitation of metal and $\mathrm{LiF}$ phase. On recharge, these precipitated phases go into the parent phase with the $\mathrm{Li}^{+}$ pumped out. Here the parent phase is the defected rocksalt phase. The lithiation of $\mathrm{FeO}_{x} \mathrm{~F}_{2-x}$ experiences intercalation-extrusionconversion reaction pathway. Since the less-reversible conversion reaction was partially replaced by a highly reversible extrusion reaction in $\mathrm{FeO}_{x} \mathrm{~F}_{2-x}(0.4<x<0.7)$, electrochemical performance was significantly enhanced (Eq. 3) ${ }^{6,31-37}$. However, the reaction kinetics, cycle life, and round-trip efficiency of $\mathrm{FeO}_{x} \mathrm{~F}_{2-x} \quad(0.4<x<0.7)$ still are far less satisfactory when compared to intercalation cathodes due to the existence of less-reversible conversion reaction.

$$
\begin{aligned}
& \text { FeOF } \mathrm{Li}^{+}+\mathrm{e}^{-} \text {intercalation } \mathrm{LiFeOF} \\
& \text { (rutile) } \longleftrightarrow \quad \text { (rutile) } \\
& \begin{array}{r}
(x+y-1) \mathrm{Li}^{+}+(x+y-1) \mathrm{e}^{-} \text {Extrusion } \mathrm{Ii}_{x} \mathrm{FeOF}_{1-y}+y \mathrm{LiF} \\
\text { (rocksalt) }
\end{array} \\
& (1.5-x-y) \mathrm{Li}^{+}+\left(\stackrel{1.5-x-y) \mathrm{e}^{-} \text {Extrusion II }}{\longleftrightarrow} 0.5 \begin{array}{c}
\mathrm{LiFeO}_{2} \\
\text { (rocksalt) }
\end{array}+\mathrm{LiF}+0.5 \mathrm{Fe}\right.
\end{aligned}
$$

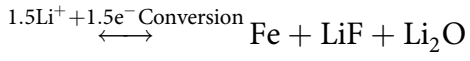

In recent years, the critical issues of high potential hysteresis $(>1 \mathrm{~V})$, poor rate capability, and limited cycling stability of conversion electrodes have been believed to be intrinsic nature of the conversion reaction chemistry, and the hope of using conversion reaction materials in the next-generation lithium batteries waned. However, it will be plausible to suppress the conversion reaction by extending the capacity of highly reversible intercalation-extrusion reaction, thus achieving both high capacity and long cycle life.

In this work, we report that such a high-performance $\mathrm{Fe}_{0.9} \mathrm{Co}_{0.1} \mathrm{OF}$ cathode with high energy density of $\sim 1000 \mathrm{Wh} \mathrm{kg}^{-1}$ and long cycle life of 1000 cycles can be realized by a costeffective and simple strategy of concerted doping $\mathrm{Co} / \mathrm{O}$ in $\mathrm{FeF}_{3}$. At a charge/discharge current of $500 \mathrm{~mA} \mathrm{~g}^{-1}$, the $\mathrm{Fe}_{0.9} \mathrm{Co}_{0.1} \mathrm{OF}$ can deliver a capacity of $350 \mathrm{mAh} \mathrm{g}^{-1}$ for 1000 cycles. The firstprinciples calculations and comprehensive characterizations revealed that the less-reversible conversion reaction was entirely prohibited by reducing the potential $f$ and the reversibility of the extrusion reaction II was significantly enhanced by formation of non-stoichiometric rocksalt phase with only $<5 \%$ of $\mathrm{Fe}(\mathrm{Co})$ phase in lithiated $\mathrm{Fe}_{0.9} \mathrm{Co}_{0.1} \mathrm{OF}$ after 100 cycles (Eq. 4), while $50 \%$ of $\mathrm{Fe}$ was reported in lithiated $\mathrm{FeO}_{x} \mathrm{~F}_{2-x}(0.4<x<0.7)^{38}$. The thermodynamic capacity reduction due to the elimination of conversion reaction was compensated by kinetic capacity increase due to the enhanced reaction kinetics of extrusion II through formation of defect-rich (especially $\mathrm{O}$ vacancies) rocksalt phase. The highly reversible structural transition in the intercalation and extrusion reactions after co-substitution significantly improved performance of $\mathrm{Fe}_{0.9} \mathrm{Co}_{0.1} \mathrm{OF}$, which provides an alternative solution to the similar challenges faced by other conversion reaction materials.

$$
\begin{aligned}
& \mathrm{Fe}(\mathrm{Co}) \mathrm{OF} \mathrm{Li}^{+}+\mathrm{e}^{-} \text {Intercalation } \mathrm{LiFe}(\mathrm{Co}) \mathrm{OF} \\
& \text { (rutile) } \longleftrightarrow \quad \text { (rutile) } \\
& \begin{array}{r}
(x+y-1) \mathrm{Li}^{+}+(x+y-1) \mathrm{e}^{-} \text {Extrusion } \mathrm{Ii}_{x} \mathrm{Fe}(\mathrm{Co}) \mathrm{OF}_{1-y}+y \mathrm{LiF} \\
\text { (rocksalt) }
\end{array} \\
& \begin{aligned}
&(1.5-x-y) \mathrm{Li}^{+}+(1.5-x-y) \mathrm{e}^{-} \text {Extrusion II } \frac{1}{2-z} \\
& \mathrm{Li}_{1-\frac{z}{2}} \mathrm{Fe}(\mathrm{Co}) \mathrm{O}_{2-z} \\
&(\text { defected rocksalt) }
\end{aligned} \\
& +\mathrm{LiF}+\left(1-\frac{1}{2-z}\right) \mathrm{Fe}(\mathrm{Co})
\end{aligned}
$$

\section{Results}

Synthesis and characterization. $\mathrm{Fe}_{0.9} \mathrm{Co}_{0.1} \mathrm{OF}$ and $\mathrm{FeOF}$ were synthesized using a solvothermal method, while $\mathrm{FeF}_{3}$ was prepared by ball milling the commercial $\mathrm{FeF}_{3}$ for $6 \mathrm{~h}$ (Supplementary Fig. 1). $\mathrm{FeF}_{3}, \mathrm{FeOF}$, and $\mathrm{Fe}_{0.9} \mathrm{Co}_{0.1} \mathrm{OF}$ powders show distinct colors: $\mathrm{FeF}_{3}$ is light green; FeOF appears brown; while $\mathrm{Fe}_{0.9} \mathrm{Co}_{0.1} \mathrm{OF}$ is dark brown (Supplementary Fig. 2). This darkening trend indicates the change of the bandgap after doping, which is verified by the density functional theory (DFT) calculations (Supplementary Fig. 3). The crystal structures of $\mathrm{FeOF}$ and $\mathrm{Fe}_{0.9} \mathrm{Co}_{0.1} \mathrm{OF}$ were 

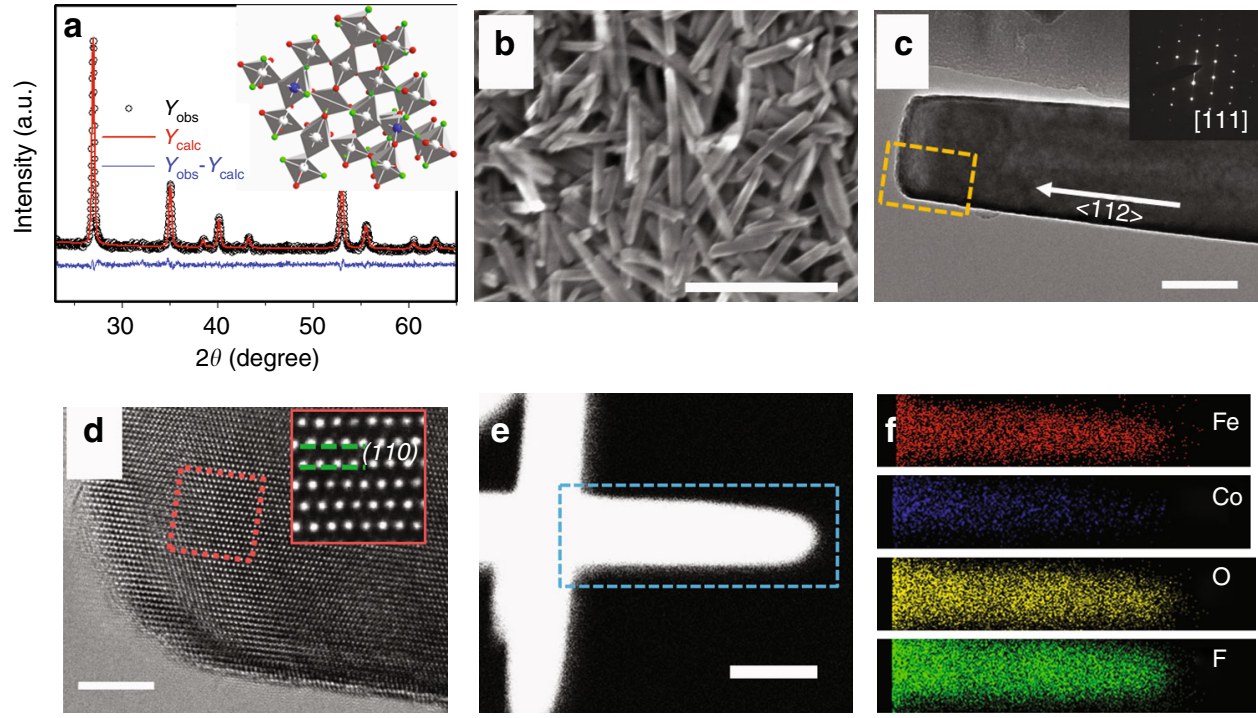

Fig. 1 Structural and morphological characterization of $\mathrm{Fe}_{0.9} \mathrm{Co}_{0.1} \mathrm{OF}$. a Rietveld refinement showing data points $\left(Y_{\text {obs, }}\right.$, black circles), calculated profile $\left(Y_{\text {calc }}\right.$ red line), and difference profile (blue line), as indicated. Refined parameters: $a=4.68(6) \AA, c=3.06(6) \AA$, which are slightly larger than those of FeOF ( $a$ $=4.647 \AA, c=3.048 \AA$ ). $\mathbf{b}$ SEM images of the $\mathrm{Fe}_{0.9} \mathrm{Co}_{0.1} \mathrm{OF}$ nanorods; $\mathbf{c}$, d TEM and HRTEM images of $\mathrm{Fe}_{0.9} \mathrm{Co}_{0.1} \mathrm{OF}$; e, $\mathbf{f}$ STEM-HAADF image of $\mathrm{Fe}_{0.9} \mathrm{Co}_{0.1} \mathrm{OF}$ nanorod and STEM-EDS elemental mapping of $\mathrm{Fe}, \mathrm{Co}, \mathrm{O}$, and $\mathrm{F}$. Inset of a: the crystal structure of $\mathrm{Fe}_{0.9} \mathrm{Co}_{0.1} \mathrm{OF}$. The insets of $\mathbf{c}$ : corresponding SAED pattern. The insets of $\mathbf{d}$ : enlargement HRTEM image of the HRTEM image. The rectangle in $\mathbf{e}$ denotes the EDS mapping area in $\mathbf{f}$. Scale bar in $\mathbf{b}$-e is $400,50,5$, and $50 \mathrm{~nm}$, respectively

examined using X-ray diffraction (XRD), scanning electron microscopy (SEM), transmission electron microscopy (TEM) and high-resolution (HR) TEM, respectively. Figure la shows the XRD pattern of $\mathrm{Fe}_{0.9} \mathrm{Co}_{0.1} \mathrm{OF}$, which has the same tetragonal rutile structure as FeOF with a slightly increased unit cell size (Supplementary Fig. 4). SEM (Fig. 1b) image reveals a uniform nanorod morphology of $\mathrm{Fe}_{0.9} \mathrm{Co}_{0.1} \mathrm{OF}$ with a diameter of about $40-50 \mathrm{~nm}$ and length of 300-400 $\mathrm{nm}$. Under the same synthesis conditions, the FeOF particle is much larger (Supplementary Fig. 5). However, by changing the solvent and the temperature, FeOF nanorods with the same size as $\mathrm{Fe}_{0.9} \mathrm{Co}_{0.1} \mathrm{OF}$ was obtained (Supplementary Fig. 6). A representative TEM image (Fig. 1c) and corresponding selected area electron diffraction (SAED) pattern at inset show the growth direction as $<112>$. HRTEM image (Fig. 1d) in Fig. 1c further reveal the lattice spacing of 0.33 $\mathrm{nm}$ ((110) plane) for one-dimensional $\mathrm{Fe}_{0.9} \mathrm{Co}_{0.1} \mathrm{OF}$ nanorods. The elemental distribution of nanorod was investigated with an energy-dispersive X-ray spectroscopy (EDS) technique in scanning TEM (STEM) mode. A high-angle annular dark-field (HAADF)-STEM image (Fig. 1e) and STEM-EDS elemental mappings (Fig. 1f) show that all four elements (Fe, Co, O, and F) are uniformly distributed throughout the nanorod, which is consistent with the cross-sectional STEM-EDS line profile of $\mathrm{Fe}_{0.9} \mathrm{Co}_{0.1} \mathrm{OF}$ nanorod (Supplementary Fig. 7 ). EDS results also show that the atomic ratio of the $\mathrm{O}: \mathrm{F}$ in $\mathrm{Fe}_{0.9} \mathrm{Co}_{0.1} \mathrm{OF}$ and $\mathrm{FeOF}$ is almost the same and close to 1 (Supplementary Fig. 8).

Electrochemical performance. An unexpected high cycling stability is achieved for $\mathrm{Fe}_{0.9} \mathrm{Co}_{0.1} \mathrm{OF}$ nanorods. Figure 2a displays a stable capacity of $350 \mathrm{mAh} \mathrm{g}^{-1}$ at a high current of $500 \mathrm{~mA} \mathrm{~g}^{-1}$ for 1000 cycles, while a higher capacity of $420 \mathrm{mAh} \mathrm{g}^{-1}$ can be achieved at a low current of $70 \mathrm{~mA} \mathrm{~g}^{-1}$ for over 330 cycles (Supplementary Fig. 9). The capacity's decay is about $0.005 \%$ at a high current of $500 \mathrm{mAg}^{-1}$, which is unprecedented for any conversion reaction materials and comparable to that of intercalation cathodes. The superior cycling stability is also evidenced by the almost identical discharge profiles at the 200th to the curves at the 100th and the 3rd cycles (Fig. 2b). The charge/ discharge profiles of $\mathrm{Fe}_{0.9} \mathrm{Co}_{0.1} \mathrm{OF}$ cathodes at $70 \mathrm{~mA} \mathrm{~g}^{-1}$ (Fig. 2b) are characterized by a declining discharge pseudo-plateau at $3.0 \mathrm{~V}$ followed by an extrusion reaction sloping line. In contrast, the $\mathrm{FeF}_{3}$ has a similar initial capacity of $\sim 400 \mathrm{mAh} \mathrm{g}^{-1}$ at the same current of $70 \mathrm{~mA} \mathrm{~g}^{-1}$ but it suffers a rapid capacity loss to 120 mAh g ${ }^{-1}$ after only 25 cycles (Supplementary Fig. 9), which is in line with the reported performance 4 . The electrochemical performance of FeOF with different nanorod size is shown in Supplementary Fig. 10. Two FeOF with different sizes show a similar initial capacity of $450 \mathrm{mAh} \mathrm{g}^{-1}$ that gradually reduced to $300 \mathrm{mAh} \mathrm{g}^{-1}$ within 100 cycles at a current of $70 \mathrm{~mA} \mathrm{~g}^{-1}$ (Supplementary Fig. 10).

$\mathrm{Fe}_{0.9} \mathrm{Co}_{0.1} \mathrm{OF}$ nanorods show much higher rate capability than those of $\mathrm{FeF}_{3}$ and FeOF (Fig. 2c, and Supplementary Fig. 11) ) $^{39,40}$. $\mathrm{Fe}_{0.9} \mathrm{Co}_{0.1} \mathrm{OF}$ delivers an enhanced capacity of $\sim 440 \mathrm{mAh} \mathrm{g}^{-1}$ at $80 \mathrm{~mA} \mathrm{~g}^{-1}$. When the current is increased to 160,320 and 640 $\mathrm{mA} \mathrm{g}^{-1}, \mathrm{Fe}_{0.9} \mathrm{Co}_{0.1} \mathrm{OF}$ still retains a reversible capacity of $\sim 400$, $\sim 380$, and $\sim 340 \mathrm{mAh} \mathrm{g}^{-1}$ (Fig. 2c and Supplementary Fig. 11), respectively, whereas FeOF shows only 300, 250, and $200 \mathrm{mAh} g$ -1 at the same rates, and $\mathrm{FeF}_{3}$ only possess a reversible capacity of $\sim 60 \mathrm{mAh} \mathrm{g}^{-1}$ at $320 \mathrm{~mA} \mathrm{~g}^{-1}$. Figure $2 \mathrm{~d}$ shows the Ragone plot of $\mathrm{FeF}_{3}, \mathrm{FeOF}$, and $\mathrm{Fe}_{0.9} \mathrm{Co}_{0.1} \mathrm{OF}$ (based on active mass). At a lower specific power (a low discharge rate), $\mathrm{FeOF}$ or $\mathrm{Fe}_{0.9} \mathrm{Co}_{0.1} \mathrm{OF}$ show a similar energy density of $1000 \mathrm{Wh} \mathrm{kg}^{-1}$. However, $\mathrm{Fe}_{0.9} \mathrm{Co}_{0.1} \mathrm{OF}$ shows the highest rate capability across the entire rate range: at $640 \mathrm{~mA} \mathrm{~g}^{-1}$, the energy density of $\mathrm{Fe}_{0.9} \mathrm{Co}_{0.1} \mathrm{OF}$ is twice that of $\mathrm{FeOF}$, or six times higher than that of $\mathrm{FeF}_{3}$, yielding the highest energy density ever reported for iron fluoride conversion reaction cathode materials at similar rates.

The electrochemical behavior of $\mathrm{Fe}_{0.9} \mathrm{Co}_{0.1} \mathrm{OF}$ was characterized using cyclic voltammetry $(\mathrm{CV})$ and galvanostatic intermittent titration technique (GITT). Figure 2e compares the CV scans of $\mathrm{Fe}_{0.9} \mathrm{Co}_{0.1} \mathrm{OF}, \mathrm{FeOF}$, and $\mathrm{FeF}_{3}$. All three fluorides experiences a highly reversible intercalation reaction peaks at around $3.0 \mathrm{~V}$. However, the followed conversion reaction peak at $1.6 \mathrm{~V}$ for $\mathrm{FeF}_{3}$ shifted to a high potential of $1.9 \mathrm{~V}$ in $\mathrm{FeOF}$ and the peak current was significantly reduced. The conversion reaction 
a

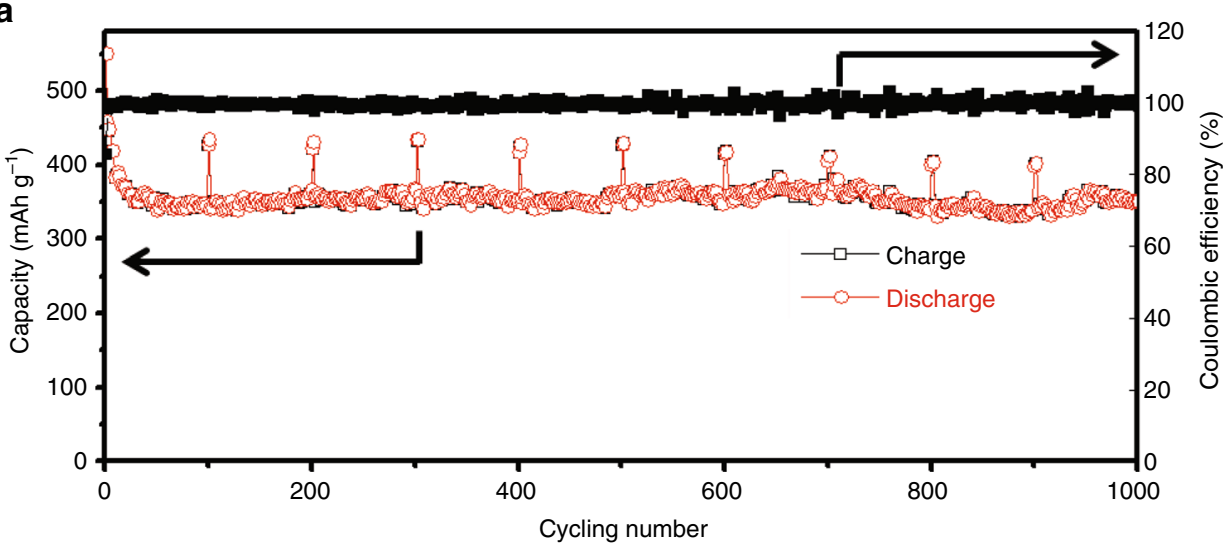

b

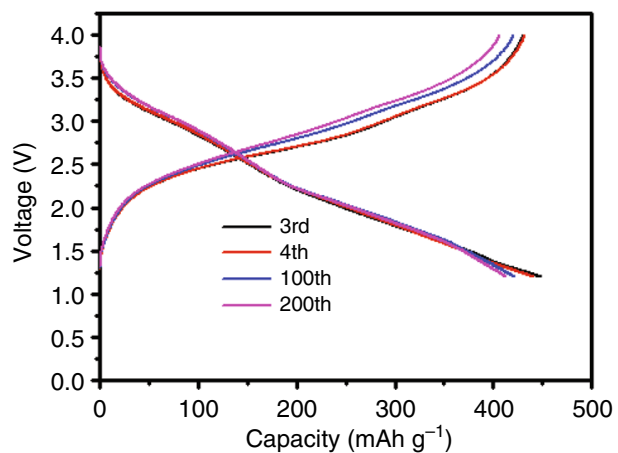

d

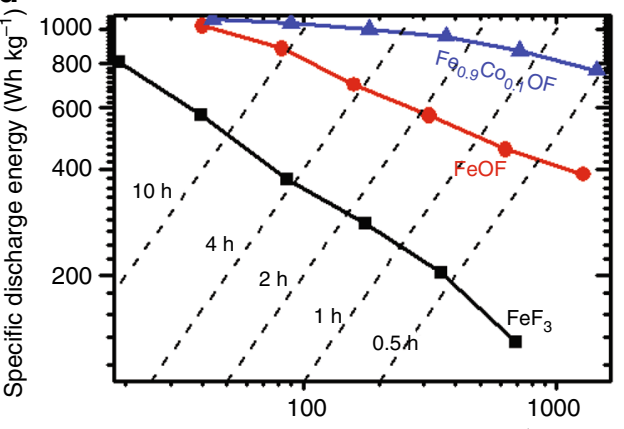

Specific discharge power $\left(\mathrm{W} \mathrm{Kg}^{-1}\right)$

$\mathbf{f}$

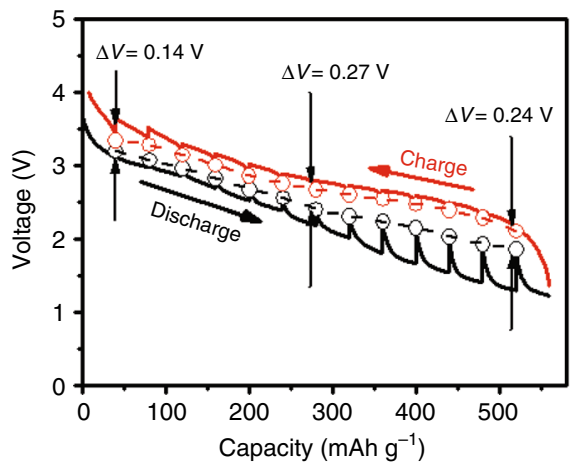

C

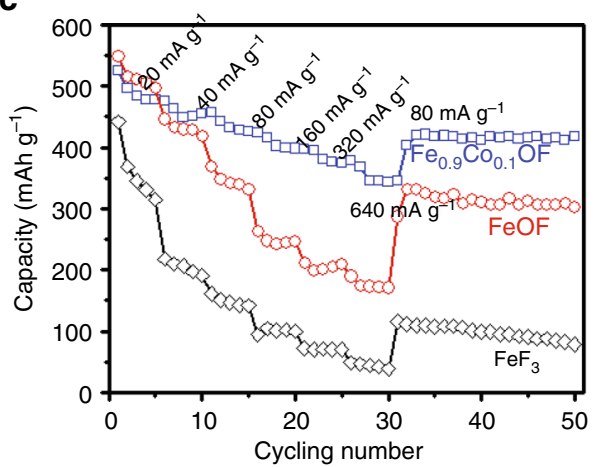

e

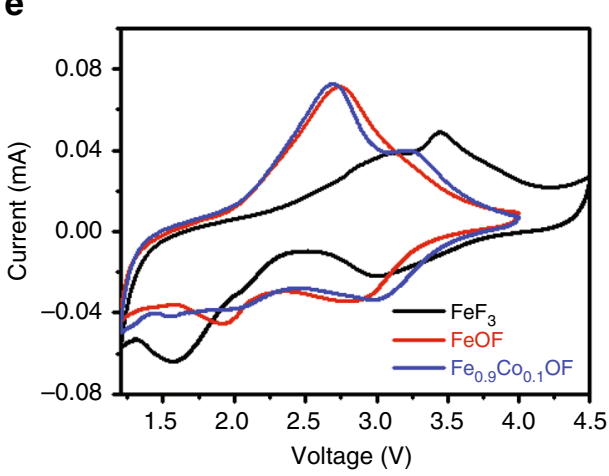

g

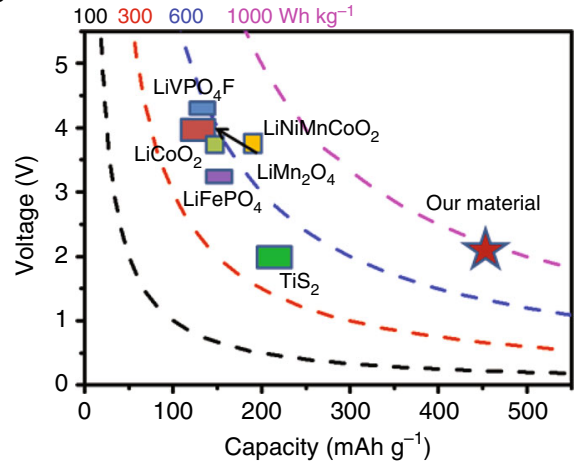

Fig. 2 Electrochemical performance of the $\mathrm{Fe}_{0.9} \mathrm{Co}_{0.1} \mathrm{OF}$ cathode. a Cycling performance for $\mathrm{Fe}_{0.9} \mathrm{Co}_{0.1} \mathrm{OF}$ cathode with a current of $500 \mathrm{mAg} \mathrm{g}^{-1}$, every 100 cycles, the current changed to $70 \mathrm{~mA} \mathrm{~g}^{-1}$ and cycled two cycles; $\mathbf{b}$ representative discharge/charge curves for $\mathrm{Fe}_{0.9} \mathrm{Co}_{0.1} \mathrm{OF}_{\text {at a current of } 70 \mathrm{~mA} \mathrm{~g}}{ }^{-1}$ in the potential range of $1.2-4.0 \mathrm{~V}$; $\mathbf{c}$ rate capability for $\mathrm{Fe}_{0.9} \mathrm{Co}_{0.1} \mathrm{OF}$, $\mathrm{FeOF}$, and $\mathrm{FeF}_{3}$ cathode materials, respectively; $\mathbf{d}$ the $\mathrm{Rag}$ one plot of $\mathrm{FeF}$, $\mathrm{FeOF}_{\text {, and }}$ $\mathrm{Fe}_{0.9} \mathrm{Co}_{0.1} \mathrm{OF}$ (based on active mass); e CV profiles for the three materials $\left(\mathrm{FeF}_{3}, \mathrm{FeOF}\right.$, and $\mathrm{Fe}_{0.9} \mathrm{Co}_{0.1} \mathrm{OF}$ ) with a scanning rate of $0.1 \mathrm{mV} \mathrm{s}{ }^{-1}$. $\mathbf{f}$ Galvanostatic intermittent titration technique (GITT) measurement of $\mathrm{Fe}_{0.9} \mathrm{Co}_{0.1} \mathrm{OF}$ ( $40 \mathrm{~mA} \mathrm{~g}^{-1}$ for $1 \mathrm{~h}$ followed by a $20 \mathrm{~h}$ rest); $\mathbf{g}$ capacity, voltage, and energy density of $\mathrm{Fe}_{0.9} \mathrm{Co}_{0.1} \mathrm{OF}$ (discharge energy density is calculated based on discharge current of $40 \mathrm{~mA} \mathrm{~g}^{-1}$ ) as compared with the intercalation cathodes 
peak completely disappeared in $\mathrm{Fe}_{0.9} \mathrm{Co}_{0.1} \mathrm{OF}$, indicating that the conversion reaction was replaced by two extrusion reactions. During delithiation, two corresponding anodic peaks can be observed. The quasi-thermodynamic potential hysteresis of $\mathrm{Fe}_{0.9} \mathrm{Co}_{0.1} \mathrm{OF}$ (Fig. 2f), FeOF, and $\mathrm{FeF}_{3}$ (Supplementary Fig. 12) were measured using GITT. The hollow circles represent quasiequilibrium potentials after fully relaxation at open circuit for 20 $\mathrm{h}$, which approximates thermodynamic values. At $50 \%$ state of charge/discharge, this potential hysteresis of $\mathrm{Fe}_{0.9} \mathrm{Co}_{0.1} \mathrm{OF}$ is only $0.27 \mathrm{~V}$ (Fig. $2 \mathrm{f}$ ), which is substantially lower than $1.1 \mathrm{~V}$ for $\mathrm{FeF}_{3}$ and $0.57 \mathrm{~V}$ for $\mathrm{FeOF}$ (Supplementary Fig. 12), respectively, and is even comparable to some intercalation-type cathodes ${ }^{41}$. The over-potential in $\mathrm{Fe}_{0.9} \mathrm{Co}_{0.1} \mathrm{OF}(170 \mathrm{mV})$ is also significantly smaller than the reaction in $\mathrm{FeOF}(286 \mathrm{mV})$ and $\mathrm{FeF}_{3}(634 \mathrm{mV})$ (Supplementary Fig. 13), and comparable to the lowest over-potential ever reported in mixed metal fluoride cathode $\left(\mathrm{Cu}_{y} \mathrm{Fe}_{1-\gamma} \mathrm{F}_{2}, 150 \mathrm{mV}\right)^{16}$. The high potential hysteresis $(>0.5 \mathrm{~V})$ for conversion fluoride cathodes is attributed to the different conversion reaction pathways during lithiation and delithiation ${ }^{6,7,20}$, which was considered as an intrinsic challenge and cannot be overcome through nanostructure design. We overcome this intrinsic issue by replacing the conversion reaction with two extrusion reactions through $\mathrm{Co}$ and $\mathrm{O}$ cosubstitution in $\mathrm{FeF}_{3}$, therefore the over-potential value of $\mathrm{Fe}_{0.9} \mathrm{Co}_{0.1} \mathrm{OF}$ calculated from the middle points of the charge/ discharge capacities is only $<1 / 3$ of the $\mathrm{FeF}_{3}$ (Supplementary Fig. 14), resulting in an energy round-trip efficiency of $>80 \%$ (Supplementary Fig. 15).

Non-lithiated $\mathrm{Fe}_{0.9} \mathrm{Co}_{0.1} \mathrm{OF}$ cathode would require a lithiated anode in a full battery as its electrochemical couple, which is extremely difficult from perspective of practical production. For an ideal cathode material to be used as drop-in replacement by LIB industry, it is desirable to exist with built-in lithium source. Hence we pre-lithiated $\mathrm{Fe}_{0.9} \mathrm{Co}_{0.1} \mathrm{OF}$ via ball milling with $\mathrm{LiH}$ (Supplementary Fig. 16). The charge/discharge curves of prelithiated $\mathrm{Fe}_{0.9} \mathrm{Co}_{0.1} \mathrm{OF}$ (Supplementary Fig. 17) exhibit a higher over-potential than its non-lithiated counterpart in the first cycle. In the subsequent cycles, however, the voltage profiles of prelithiated $\mathrm{Fe}_{0.9} \mathrm{Co}_{0.1} \mathrm{OF}$ (Supplementary Fig. 17) became almost identical to its unlithiated $\mathrm{Fe}_{0.9} \mathrm{Co}_{0.1} \mathrm{OF}$ (Fig. 2b), with a much smaller voltage hysteresis than the pre-lithiated $\mathrm{FeF}_{3}$ reported previously $y^{20,40,42}$. The cycling performance for the pre-lithiated $\mathrm{Fe}_{0.9} \mathrm{Co}_{0.1} \mathrm{OF}$ is also similar to the non-lithiated one (Supplementary Fig. 18). The high capacity combined with a high discharge voltage leads to a discharge energy density of $\sim 1000 \mathrm{Wh} \mathrm{kg}^{-1}$ at current of $40 \mathrm{~mA} \mathrm{~g}^{-1}$, which is higher than most intercalation cathode materials (Fig. 2g).

PDF and ex situ TEM characterization. The phase evolution of $\mathrm{Fe}_{0.9} \mathrm{Co}_{0.1} \mathrm{OF}$ during (de)lithiation was analyzed using X-ray pair distribution function (PDF) and compared to that of FeOF. PDF analysis is a powerful tool to study local $\mathrm{Fe}$ ordering in $\mathrm{FeOF}$ and $\mathrm{Fe}_{0.9} \mathrm{Co}_{0.1} \mathrm{OF}^{38,43,44}$. Figure 3a displays the PDF patterns of three Fe-containing phases (rutile, rocksalt, and bcc Fe metal), and the corresponding atomic structures. Figure $3 \mathrm{~b}$ shows the experimental PDF patterns of $\mathrm{FeOF}$ and $\mathrm{Fe}_{0.9} \mathrm{Co}_{0.1} \mathrm{OF}$ at pristine state, charged state after the 1st cycle, and charged state after the 100th cycle. Apparently, all PDF patterns at charged states are similar to that at the pristine, indicating reversible rutile phase formation at charged states in both $\mathrm{FeOF}$ and $\mathrm{Fe}_{0.9} \mathrm{Co}_{0.1} \mathrm{OF}$. In contrast, significant differences in PDF patterns arise at the discharged states (Fig. 3c). In these PDF patterns, the first peak at about $2.0 \AA$ corresponds to the $\mathrm{Fe}-\mathrm{O}$ and $\mathrm{Fe}-\mathrm{F}$ correlation in the oxidized $\mathrm{Fe}$ phases (rutile and rocksalt), and the second peak at $\sim 2.5 \AA$ as indicated by the red arrows in Fig. $3 c$ corresponds to the nearest Fe-Fe pairs in metallic phase ${ }^{38}$. The PDF pattern of the discharged FeOF (1st cycle) can be fitted well using rocksalt and metal phases (Supplementary Fig. 19), which contains about $60.6 \%$ of rocksalt phase and $39.4 \%$ of $\mathrm{Fe}$ (Fig. 3d). The metallic $\mathrm{Fe}(39.4 \%)$ in $\mathrm{FeOF}$ is lower (50\%) than that in oxygenless $\mathrm{FeO}_{x} \mathrm{~F}_{2-x} \quad(0.4<x<0.7)$ materials ${ }^{38}$. In discharged $\mathrm{Fe}_{0.9} \mathrm{Co}_{0.1} \mathrm{OF}$, the portion of metallic phase was further reduced to only about $13.1 \%$ while the rocksalt phase increases to $86.9 \%$ (Fig. 3d and Supplementary Fig. 19). After 100 cycles, the characteristic peak of metal in $\mathrm{Fe}_{0.9} \mathrm{Co}_{0.1} \mathrm{OF}$ becomes a broadened shoulder (Fig. 3c). Fitting results indicate that the content of metallic $\mathrm{Fe}(\mathrm{Co})$ phase was significantly reduced to about $5 \%$ while the rocksalt phase dramatically increased to 95\% (Fig. 3e). According to Wiaderek et al..$^{38}$, the lithiation of FeOF first goes through $\mathrm{Li}$ intercalation followed by phase changes from rutile to rocksalt with the extrusions of $\mathrm{Fe}$ and $\mathrm{LiF}$, and then the rocksalt phase completely decomposes into $\mathrm{Li}_{2} \mathrm{O}$ and $\mathrm{Fe}$. The PDF results suggest that the reaction natures of $\mathrm{Fe}_{0.9} \mathrm{Co}_{0.1} \mathrm{OF}$ and $\mathrm{FeOF}$ are different: for $\mathrm{Fe}_{0.9} \mathrm{Co}_{0.1} \mathrm{OF}$, conversion reaction is suppressed and the reversibility of extrusion reaction II is enhanced by suppressing the formation metallic phase through co-substitution. It indicates that the main reaction in $\mathrm{Fe}_{0.9} \mathrm{Co}_{0.1} \mathrm{OF}$ is an intercalation-extrusion reaction between rutile and rocksalt phase (Eq. 4). The mechanism for structure enhanced electrochemical performance will be discussed later.

The morphology and phase upon cycling were investigated using HRTEM, STEM, and SAED (Supplementary Fig. 20 and Fig. 3f-h). When $\mathrm{Fe}_{0.9} \mathrm{Co}_{0.1} \mathrm{OF}$ was discharged to $1.2 \mathrm{~V}$, bright contrast of small nanoparticles from STEM imaging was observed and its SAED pattern indicates that the main phase of discharged $\mathrm{Fe}_{0.9} \mathrm{Co}_{0.1} \mathrm{OF}$ is rocksalt (Fig. 3f). After being charged back to $4 \mathrm{~V}$, rocksalt phase changed back to the rutile phase (Fig. 3g). In the discharged state after 100 cycles (Fig. $3 \mathrm{~h}$ ), the rocksalt phase still dominates $\mathrm{Fe}_{0.9} \mathrm{Co}_{0.1} \mathrm{OF}$, which is consistent to the PDF results and previous reports ${ }^{38,45}$. In these SAEDs, we observed the spotty-like diffraction patterns indicating large sizes of rutile/ rocksalt grains, whereas in HAADF-STEM images, the small bright nanoparticles and its corresponding broaden rings in diffraction patterns ${ }^{33,46}$ are attributed to the metallic nanoparticles. Considering HRTEM images and their fast Fourier transform (Supplementary Fig. 20), we conclude that the rocksalt phase accounts for the main part of discharged $\mathrm{Fe}_{0.9} \mathrm{Co}_{0.1} \mathrm{OF}$ with small amount of metallic $\mathrm{Fe}(\mathrm{Co})$. In addition, the Co-doping in FeOF reduces the size of metallic nanoparticles in discharged $\mathrm{Fe}_{0.9} \mathrm{Co}_{0.1} \mathrm{OF}$. Figure $3 \mathrm{i}$ compares the size distributions of nanoparticles formed in $\mathrm{FeOF}$ and $\mathrm{Fe}_{0.9} \mathrm{Co}_{0.1} \mathrm{OF}$ after second discharging to $1.2 \mathrm{~V}$, where the $\mathrm{Fe} / \mathrm{Co}$ particle size from $\mathrm{Fe}_{0.9} \mathrm{Co}_{0.1} \mathrm{OF}$ are between 0.5 and $3.5 \mathrm{~nm}$ with an average size of $1.8 \mathrm{~nm}$, while the $\mathrm{Fe}$ particles in dicharged $\mathrm{FeOF}$ widely distributes between 2 and $5.5 \mathrm{~nm}$ with average size of $3 \mathrm{~nm}$ (Supplementary Fig. 21). In comparison, those decomposed from $\mathrm{FeF}_{3}$ are around $5 \mathrm{~nm}^{13}$. Figure $3 \mathrm{j}$ show that the rocksalt phase $\left(\mathrm{Li}_{x} \mathrm{FeO}_{2-\mathrm{y}}\right), \mathrm{Fe}$ metal, and $\mathrm{LiF}$ have similar lattice constants. The cubic-on-cubic coherence of their lattice can help to form a composite to maintain the overall shape of nanorods, thus maintaining morphology and structure integration during cycling.

In situ TEM investigation of structural evolution. The structural evolution of $\mathrm{Fe}_{0.9} \mathrm{Co}_{0.1} \mathrm{OF}$ during cycling was further investigated by in situ TEM technique with an experimental setup schematically illustrated in Fig. 4a. The time-lapse images and movie for lithiation are shown in Fig. 4b, and Supplementary Movie 1, and those for delithiation are shown in Supplementary Fig. 22 and Supplementary Movie 2, respectively. A clear contrast 
a

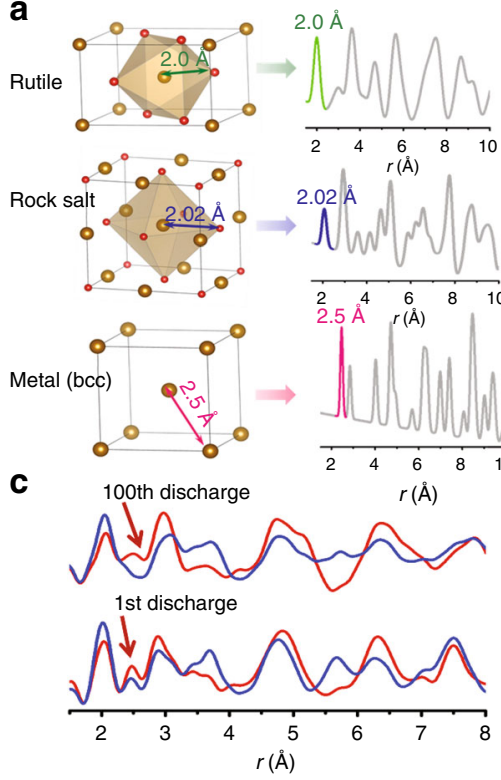

f

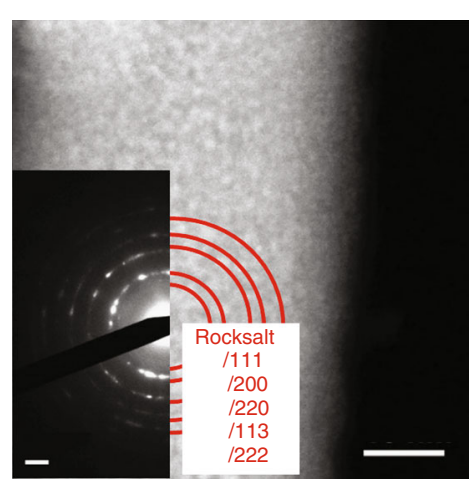

h

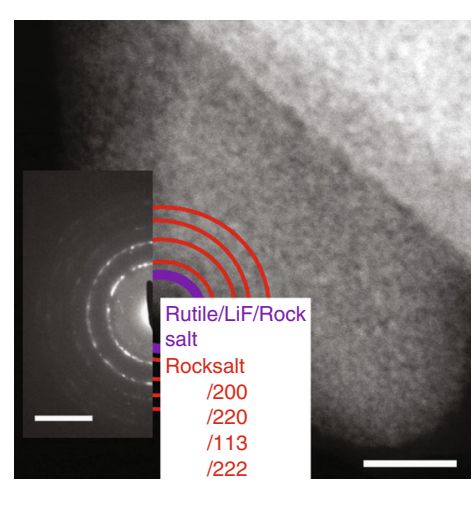

j

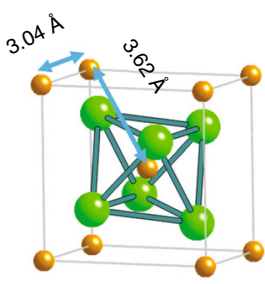

Rutile phase

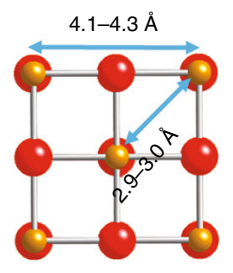

Rock-salt phase b

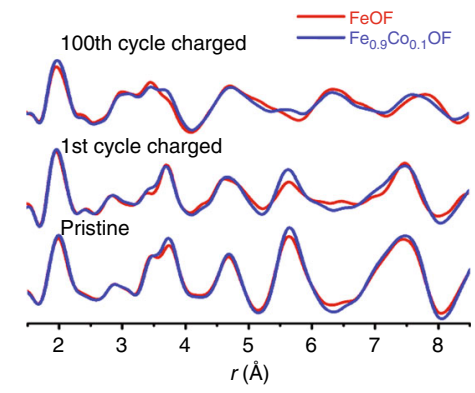

d

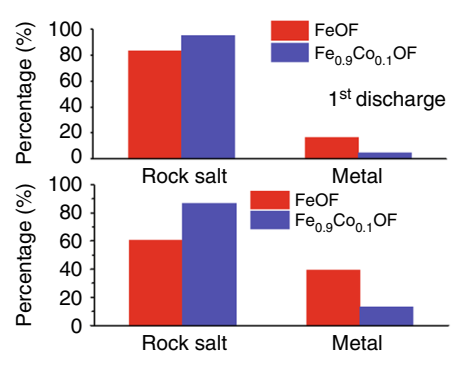

g

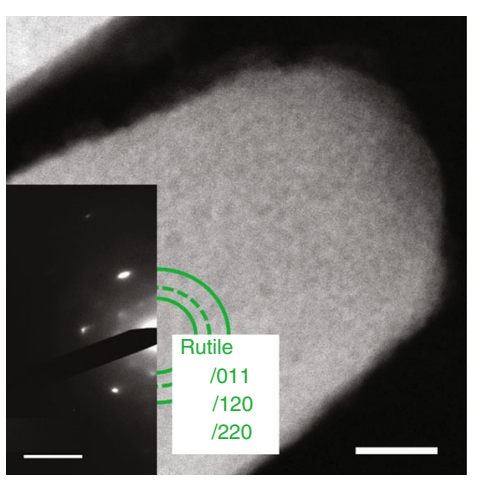

i
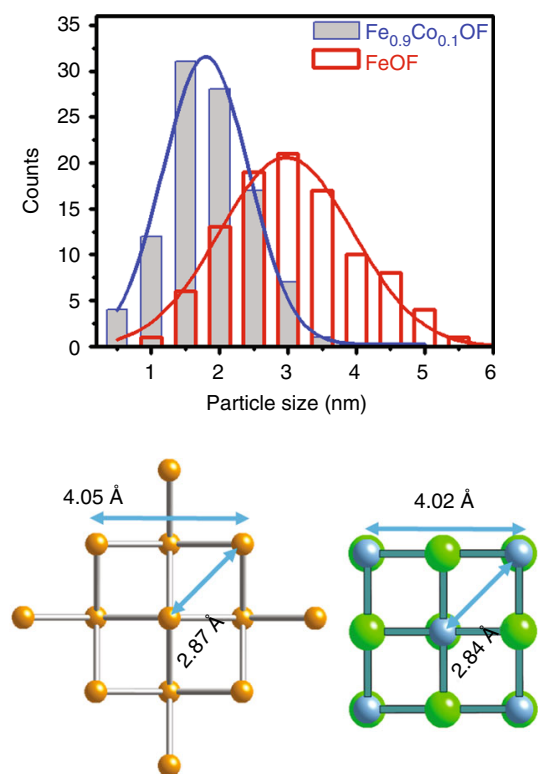

LiF phase

Fig. 3 Microstructure evolution during cycling for the $\mathrm{Fe}_{0.9} \mathrm{Co}_{0.1} \mathrm{OF}$ cathode material. a Illustration of the correspondence between PDF peaks and specific atomic pairs. b, $\mathbf{c}$ PDF patterns of $\mathrm{Fe}_{0.9} \mathrm{Co}_{0.1} \mathrm{OF}$ and FeOF for different charge and discharge states. $\mathbf{d}$, e The concentration of rocksalt phase, and the metal phase by fitting PDF results after different discharge states. f-h HRTEM images of $\mathrm{Fe}_{0.9} \mathrm{Co}_{0.1} \mathrm{OF}$ electrode after discharged to $1.2 \mathrm{~V}$, charged to $4 \mathrm{~V}$, and after 100 cycles discharged, respectively. $\mathbf{i}$ The histograms of the metal particle size distribution for $\mathrm{Fe}_{0.9} \mathrm{Co}_{0.1} \mathrm{OF}$ and FeOF electrodes after discharged to $1.2 \mathrm{~V}$. Insets in $\mathbf{f}-\mathbf{h}$ are the corresponding SAED patterns. $\mathbf{j}$ Illustration of the crystal structures of the four structures during cycling. Scale bar in $\mathbf{f}-\mathbf{h}$ is $10 \mathrm{~nm}$. Scale bar in the inset of $\mathbf{f}-\mathbf{h}$ is 2,5 , and $5 \mathrm{~nm}^{-1}$, respectively 
a
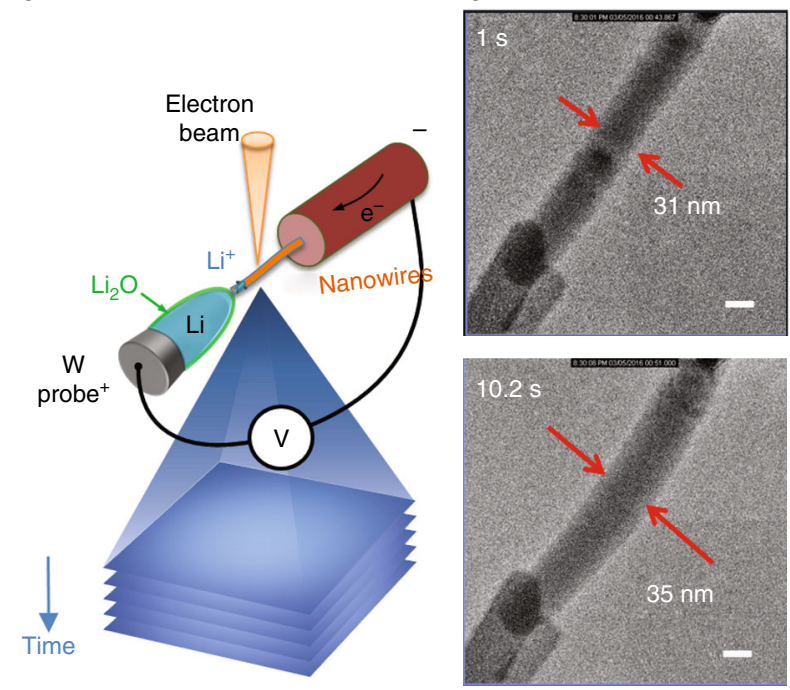

d

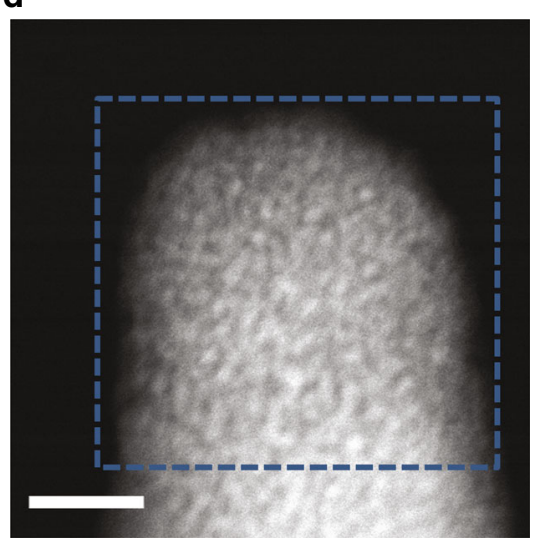

$\mathbf{e}$

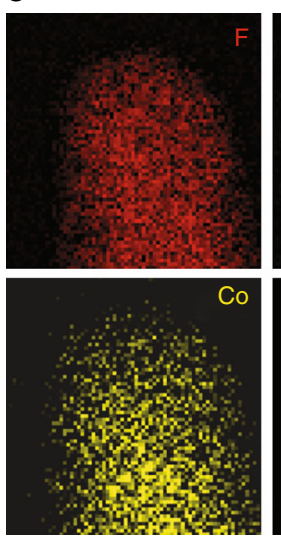

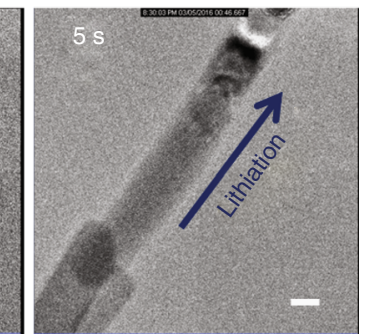

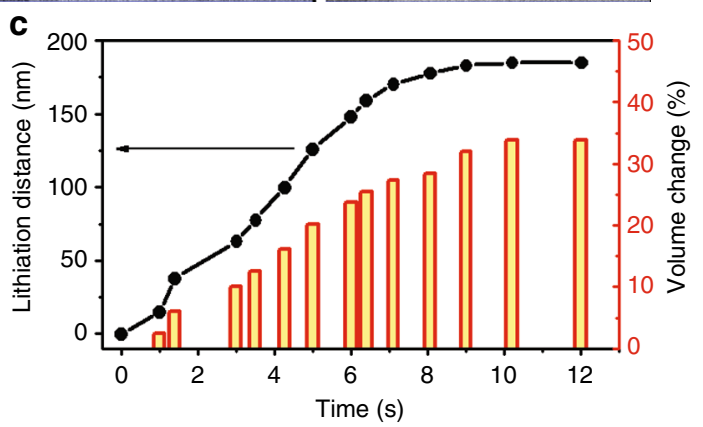

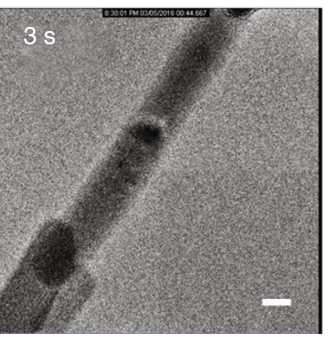

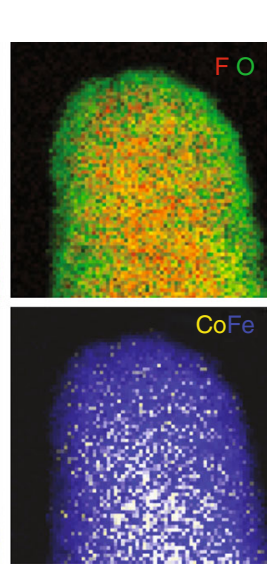

Fig. 4 Structure conversion of $\mathrm{Fe}_{0.9} \mathrm{Co}_{0.1} \mathrm{OF}$ nanorod monitored in real time and the elemental composition distribution. a Schematic illustration of the electrochemical setup for in situ TEM test. $\mathbf{b}$ In situ HRTEM image of $\mathrm{Fe}_{0.9} \mathrm{Co}_{0.1} \mathrm{OF}$ during dynamic lithiation at $1.2 \mathrm{~V}$ for different time. $\mathbf{c}$ The lithiation distance and the volume change as function of time. d ADF-STEM image and e corresponding Fe, Co, O, and F elemental distributions after the first lithiation obtained by STEM-EELS technique. Scale bar in $\mathbf{b}$ and $\mathbf{d}$ is 20 and $10 \mathrm{~nm}$, respectively

change was observed during $\mathrm{Li}$ insertion reaction ${ }^{46,47}$, and the reaction front moves rapidly across the nanorod (from the lower left to upper right). Compared with the particle-to-particle diffusion in $\mathrm{FeF}_{3}{ }^{47}, \mathrm{Fe}_{0.9} \mathrm{Co}_{0.1} \mathrm{OF}$ exhibits a much faster reaction rate without any obvious variations on surface and in bulk. Interestingly, the lithiation of a $200 \mathrm{~nm} \mathrm{Fe}_{0.9} \mathrm{Co}_{0.1} \mathrm{OF}$ nanorod occurs within only $\sim 10 \mathrm{~s}$. In comparison, for $\mathrm{FeF}_{3}$ nanoparticles with much smaller size of $\sim 10 \mathrm{~nm}$, it takes at least a few minutes for full lithiation ${ }^{47}$. Figure $4 \mathrm{c}$ compares the lithiation distance and volume change vs. time. It agrees with the electrochemical performances shown in Fig. $2 \mathrm{c}$, d, and indicates that the reaction kinetics after $\mathrm{Co} / \mathrm{O}$ co-substitution is largely improved ${ }^{12,48}$. During lithiation of $\mathrm{Fe}_{0.9} \mathrm{Co}_{0.1} \mathrm{OF}$, the nanorod volume expands by $\sim 35 \%$ with a little bend due to the stress, but no obvious cracks are observed.

The STEM-EDS results have confirmed that $\mathrm{Fe}$ and $\mathrm{Co}$ elements are homogeneously dispersed in $\mathrm{Fe}_{0.9} \mathrm{Co}_{0.1} \mathrm{OF}$ nanorods at both pristine (Fig. 1, Supplementary Fig. 7) and charged states (Supplementary Fig. 23). In addition, the chemical distributions of $\mathrm{Fe}_{0.9} \mathrm{Co}_{0.1} \mathrm{OF}$ upon cycling have been investigated using STEMelectron energy-loss spectroscopy (EELS) mapping and line-scan (Fig. 4d, e and Supplementary Fig. 24). It is found that the surface of lithiated $\mathrm{Fe}_{0.9} \mathrm{Co}_{0.1} \mathrm{OF}$ is covered with $1.5 \sim 2 \mathrm{~nm}$ oxygen-rich surface layer (Fig. 4e), which is still observed even after 100 cycles (Supplementary Fig. 24c). In Supplementary Fig. 24c, at the surface (position of $8 \mathrm{~nm}$ ), the $\mathrm{O}$ content is much higher than $\mathrm{F}$ content. However, no such layer was observed in FeOF. Instead, nano-sized domains with size of 10-20 nm were observed, where significant element segregations can be detected (Supplementary Fig. 25). We believe that the surface O-rich rocksalt layer has been effectively stabilized by Co-doping, which consequently inhibits the reaction of electrolyte with the nascent metal nanoparticles and the subsequent dissolution of transition metals into electrolytes $^{33}$. This conclusion is evidenced by the elemental analysis using inductively coupled plasma atomic emission spectroscopy (Supplementary Fig. 26), where a much lower transition metal concentration is detected in the electrolytes for $\mathrm{Fe}_{0.9} \mathrm{Co}_{0.1} \mathrm{OF}$ than that for FeOF after prolonged cycling. It should be noted that this O-rich oxide layer with thickness of $\sim 2 \mathrm{~nm}$ will not retard the Li insertion in later cycles according to DFT energy barrier calculations (Supplementary Fig. 27 and Suppementary Note 1). The diffusion barrier in $\mathrm{LiFeO}_{2}$ rocksalt phase is calculated to be $0.29 \mathrm{eV}$, which is similar to that in $\mathrm{LiFePO}_{4}$ cathode materials ${ }^{49}$. 
a

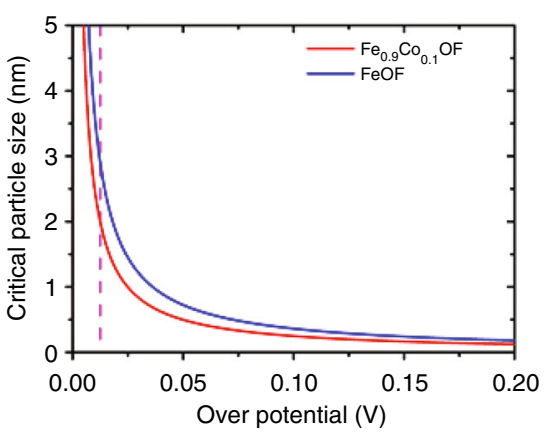

d

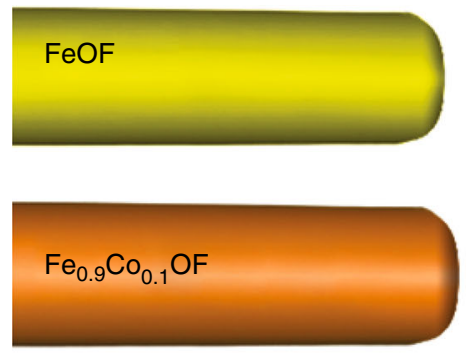

Fresh

Fe or $\mathrm{FeCo}_{x}$ b
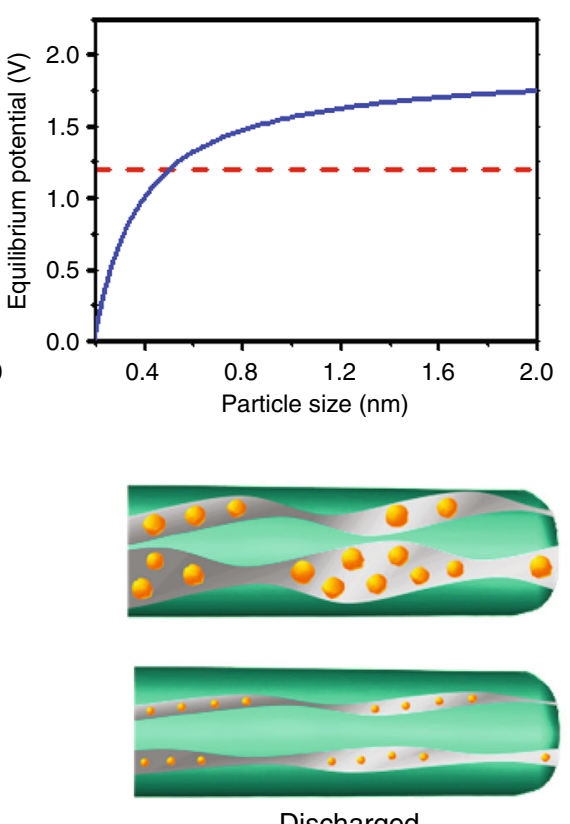

Discharged

LiF
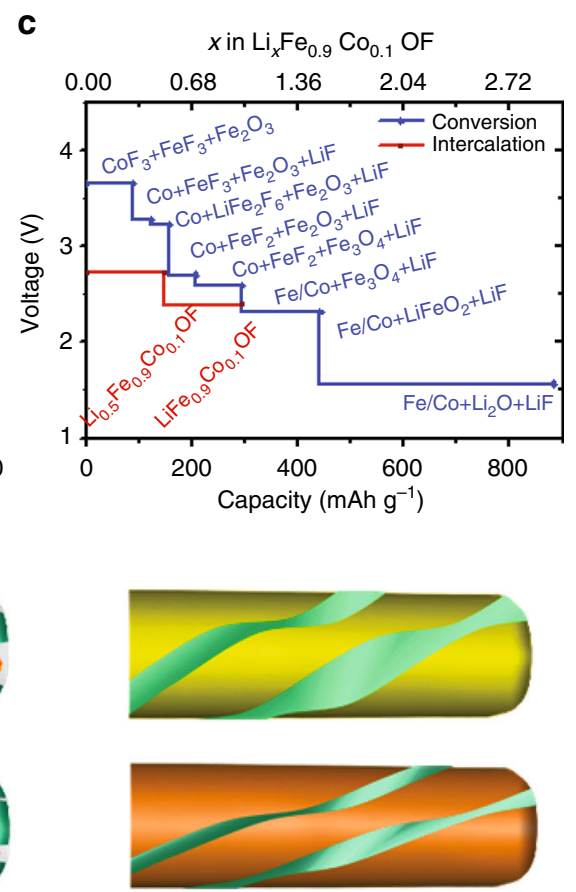

Charged

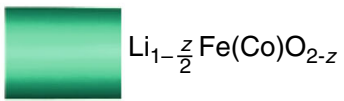

Fig. 5 Reaction mechanism for the $\mathrm{Fe}_{0.9} \mathrm{Co}_{0.1} \mathrm{OF}$ cathode. a The relationship between the overpotentials and the metal critical particle sizes during lithiation for $\mathrm{FeOF}$ and $\mathrm{Fe}_{0.9} \mathrm{Co}_{0.1} \mathrm{OF}$. $\mathbf{b}$ The relationship between the in situ-formed metal particle size with the equilibrium potential of the conversion reaction. $\mathbf{c}$ Calculation reaction curves of the $\mathrm{Fe}_{0.9} \mathrm{Co}_{0.1} \mathrm{OF}$ materials from the DFT intercalation of $\mathrm{Li}$ into $\mathrm{Fe}_{0.9} \mathrm{Co}_{0.1} \mathrm{OF}$, and the conversion path using the equilibrium phases (assuming the size of metal particles is $1 \mathrm{~nm}$ ). $\mathbf{d}$ Illustrations of structural evolution for $\mathrm{FeOF}$ and $\mathrm{Fe}_{0.9} \mathrm{Co}_{0.1} \mathrm{OF}$ during lithiation

Reaction mechanism of $\mathrm{Fe}_{\mathbf{0 . 9}} \mathrm{Co}_{\mathbf{0 . 1}} \mathrm{OF}$. From the structural characterizations using PDF and TEM, we have observed the following changes after doping Co into FeOF: (1) after the first fully lithiation, the amount of metal reduced from 39.4 to $13 \%$ while the amount of rocksalt phase significantly increased from 60.6 to $\sim 86.9 \%$. After 100 cycles, the amount of metallic phase in lithiated $\mathrm{Fe}_{0.9} \mathrm{Co}_{0.1} \mathrm{OF}$ was further reduced to $~ 5 \%$. (2) The particle size of $\mathrm{FeCo}_{x}$ in discharged state reduced from 3.0 to $1.8 \mathrm{~nm}$ and the $\mathrm{FeCo}_{x}$ particle size was further reduced during charge/ discharge cycles and almost not detectable after 100 cycles. (3) $\mathrm{Fe}_{0.9} \mathrm{Co}_{0.1} \mathrm{OF}$ possesses a stable oxygen-rich surface layer during long-term cycling.

First, it should be pointed out that similar to the $\mathrm{FeF}_{3}$, the surface energy barrier has minor impact on the Li diffusion in the $\mathrm{Fe}_{0.9} \mathrm{Co}_{0.1} \mathrm{OF}$ system according to the DFT calculation results (Supplementary Fig. 28, Supplementary Note 2, Supplementary Table 1, and Supplementary Note 3). The surface diffusion barrier $(0.88 \mathrm{eV})$ is lower than the bulk diffusion barrier $(1.36 \mathrm{eV})$ in $\mathrm{Fe}_{0.9} \mathrm{Co}_{0.1} \mathrm{OF}$. To decipher the mechanism for reducing the $\mathrm{Fe}$ particle size from Co substitution, we calculated the nucleation rate of metallic phase from interface energies during the lithiation (Supplementary Fig. 29), and the formation energy of Fe and $\mathrm{FeCo}_{x}$ particles using first-principles calculations. These calculations indicate that the formation of $\mathrm{FeCo}_{x}$ nanoparticles becomes much easier in $\mathrm{Fe}_{0.9} \mathrm{Co}_{0.1} \mathrm{OF}$, significantly reducing the critical nucleation size of $\mathrm{FeCo}_{x}$ particles in $\mathrm{Fe}_{0.9} \mathrm{Co}_{0.1} \mathrm{OF}$ compared to $\mathrm{Fe}$ particles in FeOF (Fig. 5a). The critical particle sizes of $\mathrm{FeCo}_{x}$ and
Fe at an over-potential of $0.043 \mathrm{~V}$ are 1.8 and $2.9 \mathrm{~nm}$, respectively (indicated by the dashed line in Fig. 5a), corresponding to a ratio of 3.4 for the number of particles in $\mathrm{Fe}_{0.9} \mathrm{Co}_{0.1} \mathrm{OF}$ over $\mathrm{FeOF}$ (Eq. 13), which is in consistence with the observed $\mathrm{FeCo}_{x}$ and $\mathrm{Fe}$ sizes (Fig. 3i). The reduced Fe particle size from $3.0 \mathrm{~nm}$ in FeOF to $1.8 \mathrm{~nm}$ in $\mathrm{Fe}_{0.9} \mathrm{Co}_{0.1} \mathrm{OF}$ also reduces the thermodynamic potential for conversion reaction from 1.812 to $1.729 \mathrm{~V}$ (Fig. 5c). This conversion potential will be further reduced with cycling due to continuous reduction of $\mathrm{FeCo}_{x}$ metal nanoparticle size and amount during cycles (Fig. 5b), thus conversion reaction in $\mathrm{Fe}_{0.9} \mathrm{Co}_{0.1} \mathrm{OF}$ is completely suppressed. The reduction of content and size of $\mathrm{FeCo}_{x}$ metal nanoparticle in $\mathrm{Fe}_{0.9} \mathrm{Co}_{0.1} \mathrm{OF}$ is also accompanied by formation of non-stoichiometric rocksalt phase, which significantly enhance the reversibility of extrusion II (Eq. 4). This is confirmed by disappearance of conversion peaks in $\mathrm{CV}$ for $\mathrm{Fe}_{0.9} \mathrm{Co}_{0.1} \mathrm{OF}$ (Fig. 2e) and intercalation and extrusion sloping curves in galvanostatic charge/discharge (Fig. 2b).

DFT calculations (Fig. 5c, and Supplementary Fig. 30) show the initial lithiation process an intercalation reaction (red line in Fig. 5c and Supplementary Fig. 30), and then the LiF and small amount of $\mathrm{Fe} / \mathrm{Co}$ extrude out of the $\mathrm{LiFeO}_{2}$ rocksalt phase, which is consistent to the PDF and TEM investigations (Fig. 3). Theoretically, all levels of lithiation should be "conversion phases", as shown the blue line in Fig. 5c, and Supplementary Fig. 30. However, given that the small energy difference between the intercalation and the conversion reaction, and the large kinetic barriers to the conversion reactions ${ }^{34}$, it is reasonable that 
the material intercalate lithium before it converts (red line), which is indeed in consistence with the experiment. Considering the PDF analysis of FeOF by Wiaderek et al. ${ }^{38}$, we propose the lithiation of $\mathrm{Fe}_{0.9} \mathrm{Co}_{0.1} \mathrm{OF}$ will go through a similar process, involving intercalation and two steps of extrusion reactions (Eq. 4).

On the basis of DFT calculations, ex situ/in situ TEM, and PDF analyses, the lithiation/delithiation of $\mathrm{Fe}_{0.9} \mathrm{Co}_{0.1} \mathrm{OF}$ in the first charge-discharge cycle can be described by Eq. 4 . The fully lithiated $\mathrm{Fe}_{0.9} \mathrm{Co}_{0.1} \mathrm{OF}$ consist of $87 \%$ of non-stoichiometric $\mathrm{Li}_{0.576} \mathrm{Fe}(\mathrm{Co}) \mathrm{O}_{1.15}$ and $13 \%$ of $\mathrm{Fe}(\mathrm{Co})$ as quantitatively demonstrated by PDF. The extrusion of LiF from the lithiated materials, which is similar to the lithiation reaction in layered material of $\mathrm{Cu}_{2.33} \mathrm{~V}_{4} \mathrm{O}_{11}{ }^{50}$, has fast reaction kinetics without metal accumulation due to low content of $\mathrm{Fe}(\mathrm{Co})$. After 100 cycles, the extrusion reaction II become more reversible and fast due to continues reduction of $\mathrm{Fe}(\mathrm{Co})$ content $(\sim 5 \%)$ and size. However, due to the highly defected rocksalt phase, similar capacities were achieved in the cycling. Meanwhile, the lattice coherence of discharged compounds of LiF, rocksalt phase, and metallic phase reduces the interfacial energy and help to improve the reversibility of the compound ${ }^{34}$.

A schematic illustration of comparing the (de)lithiation mechanisms of $\mathrm{FeOF}$ and $\mathrm{Fe}_{0.9} \mathrm{Co}_{0.1} \mathrm{OF}$ is shown in Fig. 5d. When $\mathrm{FeOF}$ is fully discharged to a potential of $1.2 \mathrm{~V}$, the FeOF experiences four reactions ( $\mathrm{Li}$ intercalation, extrusion I, extrusion II, and partial conversion reaction) (Eq. 3). The existence of conversion reaction in the lithiated $\mathrm{FeOF}$ after being discharged to $1.2 \mathrm{~V}$ still limited the cycling stability due to the high irreversibility of conversion reaction. In contrast, the conversion reaction in $\mathrm{Fe}_{0.9} \mathrm{Co}_{0.1} \mathrm{OF}$ is completely inhibited and the extrusion reaction II becomes more reversible with charge/discharge cycles. As shown in Supplementary Fig. 31 and Supplementary Note 4 and Note 5, the smaller particle size ensures almost half of the atoms to be located at the interface layer for $\mathrm{Fe}_{0.9} \mathrm{Co}_{0.1} \mathrm{OF}$ after lithiation, thereby facilities the extrusion reaction and limited the diffusion distance for different ions. This pronounced reduction in particle sizes and stable coherent structures between LiF, metallic phase, and rock phase (Fig. 3d), together with the stabilized O-rich rocksalt surface layer (Fig. 4e, Supplementary Fig. 24) ensure a highly homogeneous distribution of various reaction ingredients, which was proposed as a key rationale behind the unprecedented reversibility ${ }^{1}$. During charge (delithiation), $\mathrm{LiF}$ and very small amount of $\mathrm{FeCo}_{x}$ as well as rocksalt phase will convert back to rutile phase. It is worth mentioning that such reaction mechanism does not always apply for all of the fluoride systems. For example, Wang et al. ${ }^{16}$ showed that there was no intercalation reaction in the $\mathrm{Cu}_{y} \mathrm{Fe}_{1-y} \mathrm{~F}_{2}$ materials, suggesting that the nature of reaction mechanism depends on transition metal chemistries. Such dependence in fact provides possibility of tuning the reaction route through elemental doping and tailoring the synthesis route, which is exactly the motivation of this work.

\section{Discussion}

In summary, we successfully improved the cycling stability and reaction kinetics of $\mathrm{FeF}_{3}$ by a $\mathrm{Co}$ and $\mathrm{O}$ co-substitution strategy. We found that the co-substituted $\mathrm{Fe}_{0.9} \mathrm{Co}_{0.1} \mathrm{OF}$ can achieve an energy density as high as $1000 \mathrm{Wh} \mathrm{kg}^{-1}\left(420 \mathrm{mAh} \mathrm{g}^{-1}\right)$ at $70 \mathrm{~mA}$ $\mathrm{g}^{-1}$ for 330 cycles, or $350 \mathrm{mAh} \mathrm{g}^{-1}$ for 1000 cycles at a high rate of $500 \mathrm{~mA} \mathrm{~g}^{-1}$. In addition, $\mathrm{Co}$ and $\mathrm{O}$ substitution of $\mathrm{FeF}_{3}$ also significantly reduced the potential hysteresis to $0.27 \mathrm{~V}$. In-depth analysis using analytical/in situ TEM techniques, PDF analysis, and first-principles calculations have revealed that the cosubstituted anion $(\mathrm{O})$ and cation $(\mathrm{Co})$ in $\mathrm{Fe}_{0.9} \mathrm{Co}_{0.1} \mathrm{OF}$ reduced the particles size and abundances of metallic $\mathrm{Fe}(\mathrm{Co})$, thus suppressed less-reversible conversion reaction and further enhanced the reversibility of extrusion reactions. The highly reversible intercalation-extrusion reaction pathway of $\mathrm{Fe}_{0.9} \mathrm{Co}_{0.1} \mathrm{OF}$ enhances the cycling stability and reaction kinetics. Therefore, the $\mathrm{Fe}_{0.9} \mathrm{Co}_{0.1} \mathrm{OF}$ nanorods achieved exceptional cycling performance with the small hysteresis, highest round-trip energy efficiency, and improved kinetics, which can meet the critical requirements of applications for next-generation cathode materials. The effective co-substitution strategy could be applied to resolve similar reversibility issues encountered by other conversion reaction materials, such as oxides and sulfides.

\section{Methods}

Material synthesis. $\mathrm{Fe}_{0.9} \mathrm{Co}_{0.1} \mathrm{OF}$ and $\mathrm{FeOF}$ were synthesized via solvothermal method. Typically, $\mathrm{FeF}_{3} \cdot 3 \mathrm{H}_{2} \mathrm{O}$ and $\mathrm{CoF}_{3}$ were ball milled at a molar ratio of 9:1 for $30 \mathrm{~min}$ to reduce the particle size and get a homogeneous reactant mixture. Then, $170 \mathrm{mg}$ of such mixture was dispersed in 1-propanol $(75 \mathrm{ml})$ and stirred vigorously at room temperature for half an hour. The resulting suspension was transferred into a Teflon-lined $100 \mathrm{ml}$ stainless-steel autoclave reactor, and subsequently sealed and heated at $210^{\circ} \mathrm{C}$ for $24 \mathrm{~h}$ in an oven. For comparison, FeOF was also synthesized by the same procedure using pure $\mathrm{FeF}_{3} \cdot 3 \mathrm{H}_{2} \mathrm{O}$ as the starting material dispersed in butyl-alcohol. $\mathrm{FeF}_{3}$ was prepared by ball milling the as-purchased $\mathrm{FeF}_{3}$ for $6 \mathrm{~h}$. The pre-lithiation of $\mathrm{Fe}_{0.9} \mathrm{Co}_{0.1} \mathrm{OF}$ is synthesized by ball milling $\mathrm{Fe}_{0.9} \mathrm{Co}_{0.1} \mathrm{OF}$ and $\mathrm{LiH}$ at a molar ratio of $1: 2$ for $10 \mathrm{~h}$.

Material characterizations. Microstructural analyses were performed by using SEM (Hitachi SU-70) and STEM (JEOL 2100 field emission gun TEM, operated at accelerating voltage of $200 \mathrm{kV}$ ), respectively. XRD pattern was recorded by Bruker Smart1000 (Bruker AXS Inc., USA) using $\mathrm{Cu}$ Ka radiation.

PDF experiments were carried out at X-ray powder diffraction (XPD) beamline (ID28) at the National Synchrotron Light Source II, Brookhaven National Laboratory, USA, with a photon wavelength of $0.185794 \AA$. A large-area amorphous-silicon-based detector was used to collect data to high values of momentum transfer $\left(Q_{\max }=24 \AA^{-1}\right)$. The raw images were integrated using the software FIT2d $\mathrm{d}^{52}$. PDFgetX $3^{53}$ was used to correct the data for background contributions, Compton scattering, and detector effects, and to Fourier transform the data to generate $G_{(r)}$, the PDF.

$$
G_{(r)}=4 \pi r\left[\rho_{(r)}-\rho_{0}\right]=\frac{2}{\pi} \int_{0}^{\infty} Q\left[S_{(Q)}-1\right] \sin (Q r) \mathrm{dQ}
$$

Here $\rho_{(r)}$ is the microscopic pair density, $\rho_{0}$ is the average number density, and $Q$ is magnitude of the scattering vector. For elastic scattering $Q=4 \pi \sin (\theta) / \lambda$ with $2 \theta$ being the scattering angle and $\lambda$ the wavelength of the radiation used. $S_{(Q)}$ is the total scattering function. The intensity and position of peaks corresponding to the $\mathrm{Fe}-\mathrm{Fe} /$ Co bond in metallic phase $(\sim 2.5 \AA)$ were fitted by using Gaussian functions within fityk ${ }^{54}$. Structure models were refined against the PDF data within PDFgui ${ }^{55}$.

In situ TEM. A nanofactory scanning tunneling microscopy-TEM holder was used in the experiment. The holder is equipped with three-dimensional piezo-manipulator and biasing capability. $\mathrm{Fe}_{0.9} \mathrm{Co}_{0.1} \mathrm{OF}$ nanorods were attached on a tungsten probe using conducting epoxy and mounted on one side of the holder. On the other side, we mounted another tungsten rod after transferring a small piece of $\mathrm{Li}$ on its tip. The $\mathrm{Fe}_{0.9} \mathrm{Co}_{0.1} \mathrm{OF}$ nanorods and $\mathrm{Li}$ metal were then brought into contact inside the TEM. By applying voltage on the working electrode vs. the counter electrode $(\mathrm{Li})$, lithiation and delithiation processes were recorded. The experimen was performed using a JEOL 2010F TEM operating at accelerating voltage of 200 $\mathrm{kV}$. The HAADF-STEM imaging, STEM-EELS, and STEM-EDX were performed with an aberration-corrected Hitachi HD2700C STEM at $200 \mathrm{kV}$ in Brookhaven National Lab. The conversion angle and collection angles for STEM imaging are 22 and 64-341 mrad, respectively. The collection angle of EELS are from 20 to 26 mrad depending on the needs.

First-principles calculation methods. All DFT calculations were performed using the Vienna Ab initio Simulation Package ${ }^{56}$ within the projector augmented-wave approach $^{57}$, and the Perdew-Burke-Ernzerhof generalized gradient approximation (GGA) functionals ${ }^{58}$ was used. In structures containing $\mathrm{Fe}(\mathrm{Co})$ and $\mathrm{O}$ or $\mathrm{F}$, a value of $U=4.0 \mathrm{eV}(3.32 \mathrm{eV})$ was used for Fe $(\mathrm{Co})$, as pervious DFT studies. Spinpolarized total energy calculations and structure relaxations were performed. Fe and Co atoms were initialized in high-spin ferromagnetic ordering for simplicity And the parameters of DFT calculations, such as the plane-wave energy cutoff and $k$-point density, were consistent with the parameters used for the Materials Project (MP). The voltage plateaus are obtained using the calculated DFT energies of all relevant compounds in the $\mathrm{Li}-\mathrm{Fe}-\mathrm{O}-\mathrm{F}$ space from the $\mathrm{MP}^{59}$. The structural matching results were visualized using VESTA ${ }^{60}$. 
Energy of metal nanoparticles. For the reason that GGA does not capture well the energy difference between the localized $d$-states for ionic iron and cobalt in oxide or fluoride and the delocalized states in metallic iron and cobalt. To solve this problem, as proposed by Doe, the experimentally measured reaction enthalpy obtained for $\mathrm{MF}_{2}+2 \mathrm{Li}=\mathrm{M}+2 \mathrm{LiF}(\mathrm{M}=\mathrm{Fe}$ and $\mathrm{Co})$ and the energies for $\mathrm{Li}, \mathrm{FeF}_{2}$, and $\mathrm{LiF}$ are used to determine the energies of metallic $\mathrm{Fe}$ and $\mathrm{Co}^{25}$. This approach yields cohesive energies of -4.2811 and $4.3974 \mathrm{eV}$ for bulk, metallic Fe and Co, respectively, corresponding to those obtained from experiment (i.e., -4.28 and $-4.39 \mathrm{eV})$.

To evaluate the nanosize effect, the Wulff shapes of Fe and Co are constructed to give the crystal shape under equilibrium conditions. The Wulff shape is constructed by based on the elemental surface energy data form the database developed by Shyue Ping Ong group ${ }^{61}$. The weighted surface energy $\bar{\gamma}$ using this fraction is given by the following equation:

$$
\bar{\gamma}=\frac{\sum_{\{\mathrm{hkl}\}} \gamma_{\mathrm{hkl}} A_{\mathrm{hkl}}}{\sum A_{\mathrm{hkl}}}
$$

where $\gamma_{\mathrm{hkl}}$ is the surface energy obtained from the database for a unique facet existing in the Wulff shape and $A_{\mathrm{hkl}}$ is the total area of all facets in the $\{\mathrm{hkl}\}$ family in the Wullf shape. Pymatgen is used to generate slabs and calculate weighted surface energy ${ }^{61}$.

The energy of metal nanoparticle can be calculated by the following equation:

$$
E(\text { nano })=E^{\mathrm{Fit}}(\text { bulk })-\bar{\gamma} \frac{3 V_{\mathrm{M}}}{r N_{\mathrm{A}}}
$$

Over-potential and critical nucleation particle radius. The particle size was calculated by using the same approach as previous reported ${ }^{62}$. For lithiation of $\mathrm{FeOF}$ and $\mathrm{Fe}_{0.9} \mathrm{Co}_{0.1} \mathrm{OF}$ reaction below, over-potential is the driving force for nucleation. As shown in Figs. $2 \mathrm{c}$ and 3a, at a low discharge/charge rate, similar capacity $\left(\sim 480 \mathrm{mAh} \mathrm{g}^{-1}\right)$ can be obtained for $\mathrm{FeOF}$ and $\mathrm{Fe}_{0.9} \mathrm{Co}_{0.1} \mathrm{OF}$, this capacity corresponds to $1.63 \mathrm{~mol} \mathrm{Li}$ per $1 \mathrm{~mol}$ active materials ( $\mathrm{FeOF}$ or $\mathrm{Fe}_{0.9} \mathrm{Co}_{0.1} \mathrm{OF}$ ), with a decent difference of the metal particle size and the metal contents.

$$
\begin{gathered}
1.63 \mathrm{Li}+\mathrm{FeOF} \rightarrow 0.39 \mathrm{Fe}+\mathrm{LiF}+\mathrm{Li}_{0.63} \mathrm{Fe}_{0.61} \mathrm{O} \\
1.63 \mathrm{Li}+\mathrm{Fe}_{0.9} \mathrm{Co}_{0.1} \mathrm{OF} \rightarrow 0.13 \mathrm{Fe}_{0.9} \mathrm{Co}_{0.1} \\
+\mathrm{LiF}+\mathrm{Li}_{0.63} \mathrm{M}_{0.87} \mathrm{O}
\end{gathered}
$$

By assuming that the particle has a sphere shape, the formation energy $\Delta G$ of a particle can be written as a function of over-potential $\Delta \phi$ and particle size $r$.

$$
\Delta G(\Delta \phi, r)=\frac{4}{3} \pi r^{3} \cdot \frac{1}{V_{\mathrm{M}}} \cdot \frac{1.63}{x} \cdot \Delta \phi \cdot N_{\mathrm{A}}-\gamma \cdot 4 \pi r^{2}
$$

where $V_{\mathrm{M}}$ is molar volume of $\mathrm{Fe}$ or $\mathrm{Fe}_{0.9} \mathrm{Co}_{0.1}$ particle. $\gamma$ is the interface energy. $x$ is the coefficient of $\mathrm{Fe}(x=0.39)$ or $\mathrm{Fe}_{0.9} \mathrm{Co}_{0.1}(x=0.13)$ in reaction Eqs. (9) and (10), respectively. $N_{\mathrm{A}}$ is the Avogadro constant. Specific $x$ values are derived based on PDF studies. As mentioned in the manuscript, the PDF pattern of discharged $\mathrm{FeOF}$ can be well fitted by a mixture of rocksalt and metal phases, directly yielding the phase fraction of metal phase (for FeOF, $x=0.39$ ). For the Co-substituted one, the estimation of phase fraction was made based on the intensity of the characteristic peak of metal at around $2.5 \AA$ (for $\mathrm{Fe}_{0.9} \mathrm{Co}_{0.1} \mathrm{OF}, x=0.13$ ).

The critical nucleus radius is calculated by

$$
\frac{\partial G(\phi, r)}{\partial r}=0
$$

Therefore we can get the critical nucleus radius $r^{*}$

$$
r^{*}(\phi)=\frac{2 \gamma \cdot x \cdot V_{\mathrm{M}}}{1.63 \cdot \phi \cdot N_{\mathrm{A}}}
$$

The relationship between critical particle size and over-potential is shown in Fig. 4 i.

Assuming that the same amount of metal particle is converted, then the ratio of nucleation number under same over-potential can be calculated as

$$
\frac{N_{\mathrm{Fe}_{0.9} \mathrm{Co}_{0.1}}(\Delta \phi)}{N_{\mathrm{Fe}}(\Delta \phi)}=\left(\frac{1 / r_{\mathrm{Fe}_{0.9} \mathrm{Co}_{0.1}}^{*}(\Delta \phi)}{1 / r_{\mathrm{Fe}}^{*}(\Delta \phi)}\right)^{3}
$$

Electrochemical tests. The electrochemical tests were performed using a coin-type half cell (CR 2032). Metallic lithium was used as the negative electrode. To prepare working electrode, the as-synthesized $\mathrm{Fe}_{0.9} \mathrm{Co}_{0.1} \mathrm{OF}$ (or $\mathrm{FeOF}, \mathrm{FeF}_{3}$ ), carbon black, and polyvinylidene fluoride with mass ratio 70:15:15 were mixed into a homogeneous slurry in NMP with pestle and mortar. The slurry mixture was coated onto $\mathrm{Al}$ foil and then dried at $100^{\circ} \mathrm{C}$ for $12 \mathrm{~h}$ under air atmosphere. For the pre-lithiated $\mathrm{Fe}_{0.9} \mathrm{Co}_{0.1} \mathrm{OF}$ materials, all of the preparing procedures for the electrode were protected by Ar to avoid the possible oxidation of in situ-formed Fe nanoparticles. The electrolyte consists of $1.0 \mathrm{M} \mathrm{LiPF}_{6}$ dissolved in mixture of fluoroethylene carbonate, 2,2,2-trifluoroethyl methyl carbonate, and 1,1,2,2-tetrafluoroethyl$2^{\prime}, 2^{\prime}, 3^{\prime}, 3^{\prime}$-tetrafluoropropyl-ether (HFE) at the weight ratio of 20:60:20. The cells were assembled with a polypropylene microporous film (Celgard 3501) as the separator. Electrochemical performance was tested using Arbin battery test station (BT2000, Arbin Instruments, USA). Capacity was calculated on the basis of the mass of active species $\left(\mathrm{Fe}_{0.9} \mathrm{Co}_{0.1} \mathrm{OF}, \mathrm{FeOF}\right.$, or $\left.\mathrm{FeF}_{3}\right)$. The energy density of the cathode was machine generated on the Arbin Instruments. Cyclic voltammogram scanned at $0.1 \mathrm{mV} \mathrm{s}^{-1}$ between 1.2 and $4.5 \mathrm{~V}$ was recorded using a $\mathrm{CHI} 600 \mathrm{E}$ electrochemical workstation (CH Instruments Inc., USA).

Data availability. All relevant data are available from the authors on request.

Received: 21 November 2017 Accepted: 24 April 2018

Published online: 13 June 2018

\section{References}

1. Whittingham, M. S. Ultimate limits to intercalation reactions for lithium batteries. Chem. Rev. 114, 11414-11443 (2014).

2. Etacheri, V., Marom, R., Elazari, R., Salitra, G. \& Aurbach, D. Challenges in the development of advanced Li-ion batteries: a review. Energy Environ. Sci. 4 3243-3262 (2011).

3. Arico, A. S., Bruce, P., Scrosati, B., Tarascon, J.-M. \& van Schalkwijk, W. Nanostructured materials for advanced energy conversion and storage devices. Nat. Mater. 4, 366-377 (2005).

4. Li, L., Meng, F. \& Jin, S. High-capacity lithium-ion battery conversion cathodes based on iron fluoride nanowires and insights into the conversion mechanism. Nano Lett. 12, 6030-6037 (2012).

5. Andre, D. Future generations of cathode materials: an automotive industry perspective. J. Mater. Chem. A 3, 6709-6732 (2015).

6. Ko, J. K. et al. Transport, phase reactions, and hysteresis of iron fluoride and oxyfluoride conversion electrode materials for lithium batteries. ACS Appl. Mater. Interfaces 6, 10858-10869 (2014).

7. Liu, P., Vajo, J. J., Wang, J. S., Li, W. \& Liu, J. Thermodynamics and kinetics of the $\mathrm{Li} / \mathrm{FeF}_{3}$ reaction by electrochemical Analysis. J. Phys. Chem. C 116, 6467-6473 (2012).

8. Li, L. et al. Origins of large voltage hysteresis in high-energy-density metal fluoride lithium-ion battery conversion electrodes. J. Am. Chem. Soc. 138, 2838-2848 (2016).

9. Yamakawa, N., Jiang, M., Key, B. \& Grey, C. P. Identifying the local structures formed during lithiation of the conversion material, iron fluoride, in a $\mathrm{Li}$ ion battery: a solid-state NMR, X-ray diffraction, and pair distribution function analysis study. J. Am. Chem. Soc. 131, 10525-10536 (2009).

10. Ma, Y. \& Garofalini, S. H. Atomistic insights into the conversion reaction in iron fluoride: a dynamically adaptive force field approach. J. Am. Chem. Soc. 134, 8205-8211 (2012).

11. Badway, F., Pereira, N., Cosandey, F. \& Amatucci, G. G. Carbon-metal fluoride nanocomposites: structure and electrochemistry of $\mathrm{FeF}_{3}$ : C. J. Electrochem. Soc. 150, A1209-A1218 (2003).

12. Badway, F., Cosandey, F., Pereira, N. \& Amatucci, G. G. Carbon metal fluoride nanocomposites: high-capacity reversible metal fluoride conversion materials as rechargeable positive electrodes for Li batteries. J. Electrochem. Soc. 150, A1318-A1327 (2003).

13. Wang, F. et al. Conversion reaction mechanisms in lithium ion batteries: study of the binary metal fluoride electrodes. J. Am. Chem. Soc. 133, 18828-18836 (2011).

14. Yamakawa, N., Jiang, M. \& Grey, C. P. Investigation of the conversion reaction mechanisms for binary copper(II) compounds by solid-state NMR spectroscopy and X-ray diffraction. Chem. Mater. 21, 3162-3176 (2009).

15. Hua, $\mathrm{X}$. et al. Comprehensive study of the $\mathrm{CuF}_{2}$ conversion reaction mechanism in a lithium ion battery. J. Phys. Chem. C 118, 15169-15184 (2014).

16. Wang, F. et al. Ternary metal fluorides as high-energy cathodes with low cycling hysteresis. Nat. Commun. 6, 6668 (2015).

17. Reddy, M. A. et al. $\mathrm{CF}_{x}$ derived carbon- $\mathrm{FeF}_{2}$ nanocomposites for reversible lithium storage. Adv. Energy Mater. 3, 308-313 (2013). 
18. Armstrong, M. J., Panneerselvam, A., O’Regan, C., Morris, M. A. \& Holmes, J. D. Supercritical-fluid synthesis of $\mathrm{FeF}_{2}$ and $\mathrm{CoF}_{2} \mathrm{Li}$-ion conversion materials. $J$. Mater. Chem. A 1, 10667-10676 (2013).

19. $\mathrm{Ma}, \mathrm{R}$. et al. Fabrication of $\mathrm{FeF}_{3}$ nanocrystals dispersed into a porous carbon matrix as a high performance cathode material for lithium ion batteries. $J$. Mater. Chem. A 1, 15060-15067 (2013).

20. Fan, X. et al. Pomegranate-structured conversion-reaction cathode with a built-in Li source for high-energy Li-ion batteries. ACS Nano 10, 5567-5577 (2016).

21. Fan, $\mathrm{X}$. et al. In situ lithiated $\mathrm{FeF}_{3} / \mathrm{C}$ nanocomposite as high energy conversion-reaction cathode for lithium-ion batteries. J. Power Sources 307, 435-442 (2016).

22. Kumagae, K. et al. Improvement of cycling performance of $\mathrm{FeF}_{3}$-based lithium-ion battery by boron-based additives. J. Electrochem. Soc. 163 , A1633-A1636 (2016).

23. Gu, W., Magasinski, A., Zdyrko, B. \& Yushin, G. Metal fluorides nanoconfined in carbon nanopores as reversible high capacity cathodes for $\mathrm{Li}$ and $\mathrm{Li}$-ion rechargeable batteries: $\mathrm{FeF}_{2}$ as an example. Adv. Energy Mater. 5, 1401148 (2015).

24. Li, C., Mu, X., van Aken, P. A. \& Maier, J. A high-capacity cathode for lithium batteries consisting of porous microspheres of highly amorphized iron fluoride densified from its open parent phase. Adv. Energy Mater. 3, 113-119 (2013).

25. Doe, R. E., Persson, K. A., Meng, Y. S. \& Ceder, G. First-principles investigation of the $\mathrm{Li}-\mathrm{Fe}-\mathrm{F}$ phase diagram and equilibrium and nonequilibrium conversion reactions of iron fluorides with lithium. Chem. Mater. 20, 5274-5283 (2008).

26. Zhang, W., Ma, L., Yue, H. \& Yang, Y. Synthesis and characterization of in situ $\mathrm{Fe}_{2} \mathrm{O}_{3}$-coated $\mathrm{FeF}_{3}$ cathode materials for rechargeable lithium batteries. J. Mater. Chem. 22, 24769-24775 (2012).

27. Sina, M. et al. Investigation of SEI layer formation in conversion iron fluoride cathodes by combined STEM/EELS and XPS. J. Phys. Chem. C 119, 9762-9773 (2015).

28. Sun, Y. et al. In situ chemical synthesis of lithium fluoride/metal nanocomposite for high capacity prelithiation of cathodes. Nano Lett. 16, 1497-1501 (2016).

29. Ma, D. et al. Three-dimensionally ordered macroporous $\mathrm{FeF}_{3}$ and its in situ homogenous polymerization coating for high energy and power density lithium ion batteries. Energy Environ. Sci. 5, 8538-8542 (2012).

30. Kim, S. W., Seo, D. H., Gwon, H., Kim, J. \& Kang, K. Fabrication of $\mathrm{FeF}_{3}$ nanoflowers on CNT branches and their application to high power lithium rechargeable batteries. Adv. Mater. 22, 5260-5264 (2010).

31. Zhu, J. \& Deng, D. Wet-chemical synthesis of phase-pure FeOF nanorods as high-capacity cathodes for sodium-ion batteries. Angew. Chem. Int. Ed. 54, 3079-3083 (2015).

32. Rao, K., Pereira, N., Amatucci, G. \& Cosandey, F. Electron energy loss spectroscopy study of $\mathrm{Li}$ in lithiated $\mathrm{FeOF} / \mathrm{C}$ nanocomposite battery materials. Microsc. Microanal. 16, 1440-1441 (2010).

33. Kim, S. W. et al. Structure stabilization by mixed anions in oxyfluoride cathodes for high-energy lithium batteries. ACS Nano 9, 10076-10084 (2015).

34. Chevrier, V. L., Hautier, G., Ong, S. P., Doe, R. E. \& Ceder, G. First-principles study of iron oxyfluorides and lithiation of FeOF. Phys. Rev. B 87, 094118 (2013).

35. Fan, X. et al. PEDOT encapsulated FeOF nanorod cathodes for high energy lithium-ion batteries. Nano Lett. 15, 7650-7656 (2015).

36. Pereira, N., Badway, F., Wartelsky, M., Gunn, S. \& Amatucci, G. G. Iron oxyfluorides as high capacity cathode materials for lithium batteries. J. Electrochem. Soc. 156, A407-A416 (2009).

37. Kitajou, A., Komatsu, H., Nagano, R. \& Okada, S. Synthesis of FeOF using roll-quenching method and the cathode properties for lithium-ion battery. $J$. Power Sources 243, 494-498 (2013).

38. Wiaderek, K. M. et al. Comprehensive insights into the structural and chemical changes in mixed-anion FeOF electrodes by using operando PDF and NMR spectroscopy. J. Am. Chem. Soc. 135, 4070-4078 (2013)

39. Tan, H. J. et al. Electrochemical cycling and lithium insertion in nanostructured $\mathrm{FeF}_{3}$ cathodes. J. Electrochem. Soc. 161, A445-A449 (2014).

40. Prakash, R. et al. Modified synthesis of [Fe/LiF/C] nanocomposite, and its application as conversion cathode material in lithium batteries. J. Power Sources 196, 5936-5944 (2011).

41. Kasai, M. et al. Electrochemical study on $x \mathrm{Li}_{2} \mathrm{MnO}_{3-(1-\mathrm{x})} \mathrm{LiNi}_{1 / 3} \mathrm{Co}_{1 / 3} \mathrm{Mn}_{1 / 3} \mathrm{O}_{2}$ $(x=0.5)$ layered complex cathode showing voltage hysteresis. Electrochim. Acta 146, 79-88 (2014).

42. Amatucci, G. G. et al. Formation of lithium fluoride/metal nanocomposites for energy storage through solid state reduciton of metal fluorides. J. Fluor. Chem. 132, 1086-1094 (2011)
43. Wiaderek, K. M. et al. Mesoscale effects in electrochemical conversion: coupling of chemistry to atomic- and nanoscale structure in iron-based electrodes. J. Am. Chem. Soc. 136, 6211-6214 (2014).

44. Hu, Y.-Y. et al. Origin of additional capacities in metal oxide lithium-ion battery electrodes. Nat. Mater. 12, 1130-1136 (2013).

45. Sina, M. et al. Structural phase transformation and Fe valence evolution in $\mathrm{FeO}_{x} \mathrm{~F}_{2-x} / \mathrm{C}$ nanocomposite electrodes during lithiation and de-lithiation processes. J. Mater. Chem. A 1, 11629-11640 (2013).

46. $\mathrm{He}, \mathrm{K}$. et al. Sodiation via heterogeneous disproportionation in $\mathrm{FeF}_{2}$ electrodes for sodium-ion batteries. ACS Nano 8, 7251-7259 (2014).

47. Wang, F. et al. Tracking lithium transport and electrochemical reactions in nanoparticles. Nat. Commun. 3, 1201 (2012).

48. Plitz, I. et al. Structure and electrochemistry of carbon-metal fluoride nanocomposites fabricated by solid-state redox conversion reaction. $J$. Electrochem. Soc. 152, A307-A315 (2005).

49. Dather, G. K. P., Sheppard, D., Stevenson, K. J. \& Henkelman, G. Calculations of Li-ion diffusion in olivine phosphates. Chem. Mater. 23, 4032-4037 (2011).

50. Morcrette, M. et al. A reversible copper extrusion-insertion electrode for rechargeable Li batteries. Nat. Mater. 2, 755-761 (2003).

51. Zhu, C., Mu, X., van Aken, P. A., Yu, Y. \& Maier, J. Single-layered ultrasmall nanoplates of $\mathrm{MoS}_{2}$ embedded in carbon nanofibers with excellent electrochemical performance for lithium and sodium storage. Angew. Chem. Int. Ed. 53, 2152-2156 (2014)

52. Hammersley, A. P., Svensson, S. O., Hanfland, M., Fitch, A. N. \& Hausermann, D. Two-dimensional detector software: From real detector to idealised image or two-theta scan. High. Press. Res. 14, 235-248 (1996).

53. Juhás, P., Davis, T., Farrow, C. L. \& Billinge, S. J. L. PDFgetX3: a rapid and highly automatable program for processing powder diffraction data into total scattering pair distribution functions. J. Appl. Crystallogr. 46, 560-566 (2013).

54. Wojdyr, M. Fityk: a general-purpose peak fitting program. J. Appl. Crystallogr. 43, 1126-1128 (2010).

55. Farrow, C. L. et al. PDFfit 2 and PDFgui: computer programs for studying nanostructure in crystals. J. Phys. Condens. Matter 19, 335219 (2007).

56. Kresse, G. \& Furthmüller, J. Efficient iterative schemes for ab initio totalenergy calculations using a plane-wave basis set. Phys. Rev. B 54, 11169-11186 (1996).

57. Blöchl, P. E. Projector augmented-wave method. Phys. Rev. B 50, 17953-17979 (1994).

58. Perdew, J. P., Ernzerhof, M. \& Burke, K. Rationale for mixing exact exchange with density functional approximations. J. Chem. Phys. 105, 9982-9985 (1996).

59. Ping Ong, S., Wang, L., Kang, B. \& Ceder, G. Li-Fe-P-O $\mathrm{O}_{2}$ phase diagram from first principles calculations. Chem. Mater. 20, 1798-1807 (2008).

60. Momma, K. \& Izumi, F. VESTA 3 for three-dimensional visualization of crystal, volumetric and morphology data. J. Appl. Crystallogr. 44, 1272-1276 (2011).

61. Tran, R. et al. Surface energies of elemental crystals. Sci. Data 3, 160080 (2016).

62. Kang, S., Mo, Y., Ong, S. P. \& Ceder, G. Nanoscale stabilization of sodium oxides: implications for $\mathrm{Na}-\mathrm{O}_{2}$ batteries. Nano Lett. 14, 1016-1020 (2014).

\section{Acknowledgements}

X.F. and C.W. acknowledge the financial support from Army Research Lab under Award Number W911NF1420031. Daikin America provided the high purity fluorinated solvents. The PDF data were collected at XPD beamline (28ID-2) of NSLSII, and the electron microscopy analysis was carried out at the Center for Functional Nanomaterials, Brookhaven National Laboratory (BNL), which is supported by the DOE, Office of Basic Energy Sciences, under contract DE-SC0012704. The PDF studies at BNL were supported by the Assistant Secretary for Energy Efficiency and Renewable Energy, Office of Vehicle Technologies of the U.S. Department of Energy through the Advanced Battery Materials Research (BMR) Program, including Battery500 Consortium under contract DESC0012704. C.W. and K.X. also acknowledge the support of EERE of USDOE through Battery500 Consortium Seeding project under contract DE-EE0008200. The authors acknowledge the University of Maryland supercomputing resources (http://hpcc.umd. edu) made available for conducting DFT computations in this paper. We also appreciate Dr. Qingping Meng at BNL, and Dr. Nancy J. Dudney at Oak Ridge National Laboratory (ORNL) for the constructive discussions.

\section{Author contributions}

X.F. made the samples. E.H. and X.-Q.Y. performed the PDF experiments. X.J., Y.Z., and Y.M. conducted the calculations. F.H., S.H., J.L., S.B., Z.M., T.G., S.-C.L., and J.B. designed the experiments. K.X. screened and prepared the electrolytes. X.F., E.H., D.S., 
and C.W. analyzed the experiments. X.F. wrote the draft manuscript. E.H., D.S., K.X., and C.W. revised the manuscript.

\section{Additional information}

Supplementary Information accompanies this paper at https://doi.org/10.1038/s41467018-04476-2.

Competing interests: The authors declare no competing interests.

Reprints and permission information is available online at http://npg.nature.com/ reprintsandpermissions/

Publisher's note: Springer Nature remains neutral with regard to jurisdictional claims in published maps and institutional affiliations. (c) (i) Open Access This article is licensed under a Creative Commons Attribution 4.0 International License, which permits use, sharing, adaptation, distribution and reproduction in any medium or format, as long as you give appropriate credit to the original author(s) and the source, provide a link to the Creative Commons license, and indicate if changes were made. The images or other third party material in this article are included in the article's Creative Commons license, unless indicated otherwise in a credit line to the material. If material is not included in the article's Creative Commons license and your intended use is not permitted by statutory regulation or exceeds the permitted use, you will need to obtain permission directly from the copyright holder. To view a copy of this license, visit http://creativecommons.org/ licenses/by/4.0/.

(C) The Author(s) 2018 